\title{
La calidad del empleo y sus consecuencias para el mercado de trabajo de las medianas y grandes empresas y del sector público de Argentina*
}

\author{
MóniCA JimÉnez
}

\begin{abstract}
RESUMEN
Este artículo tiene por objetivo investigar si la heterogeneidad laboral presente en las MGEySP, durante 1995-2014, pudo haber generado una segmentación más compleja que la relacionada con la existencia de trabajadores formales e informales. Para ello se analizan distintas hipótesis de segmentación considerando las características de los puestos de trabajo desde la noción de calidad del empleo introducida por OIT (2002). El período bajo estudio permite considerar diferentes escenarios laborales, económicos y sociales. Pese a que más del 78\% de los trabajadores se desempeñan en las MGEySP, la literatura le ha prestado poca atención debido a los supuestos que se realizan sobre sus características y funcionamiento. Asimismo, la hipótesis de estudio cuestiona los estudios en Argentina que sostienen que la segmentación laboral se produce exclusivamente como consecuencia del empleo informal o al interior del sector informal. La evidencia confirma algunas hipótesis de segmentación formuladas y la presencia de una estructura compleja.
\end{abstract}

Palabras clave: informalidad laboral; calidad del empleo; medianas y grandes empresas; sector público; segmentación laboral.

Clasificación JEL: J30-J38 J42 J81 O17

\section{Job Quality and Its Consequences For The Workforce of Large, Medium-Sized, and Public-Sector Companies in Argentina}

\begin{abstract}
This article aims to investigate whether this labor heterogeneity within large, medium-sized and public-sector companies (MGEySP) during 1995-2014 could have generated a more complex segmentation related to the existence of formal and informal workers. For this segmentation, different scenarios are analyzed considering the characteristics of jobs based on the notion of job quality introduced by ILO (2002). The period under study allows consideration of different labor, economic and social settings. Although more than 78\% of workers work for MGEySP, the literature has paid little attention to them because of the assumptions that are made about their features and operation. Also, this paper questions the studies in Argentina which argue that labor

\footnotetext{
* Agradezco los comentarios de los doctores Inmaculada Cebrián López, Gloria Moreno, Fabio Bertranou, Santos Ruesga y Enrique López Bazo

** Universidad Nacional de Salta
} 
segmentation occurs only as a result of informal employment or employment within the informal sector. The evidence confirms some assumptions made about segmentation and the presence of a complex structure.

Keywords: labor informality; job quality; medium and large enterprises; public sector; labor segmentation.

JEL classification: J30-J38 J42 J81 O17

\section{INTRODUCCIÓN}

La informalidad en el mercado laboral es una característica estructural y común de los países de América Latina y el Caribe (Gasparini y Tornarolli, 2007). Su análisis resulta altamente relevante en Argentina pues se trata de un fenómeno que reviste de una gravedad más que significativa, tanto por su persistencia en el tiempo como por su magnitud, a pesar de ser foco de diversas políticas públicas (OIT, 2008). Si bien este problema afecta tanto a empleados en relación de dependencia como a trabajadores independientes, la mayor parte de la fuerza laboral en Argentina es asalariada. Así, durante 1995-2014, entre el 68\% y el 75\% de los trabajadores argentinos trabaja en relación de dependencia. Además, los sistemas contributivos de la seguridad social y de las regulaciones laborales han sido diseñados originalmente para los empleados en relación de dependencia (OIT, 2011). En este artículo se considera que los asalariados tienen un empleo informal si su relación de trabajo no está conforme con la legislación laboral y, en consecuencia, están privados de los derechos y beneficios provenientes de la seguridad social (OIT, 2011). Específicamente, la informalidad se define como la falta de registro de la relación laboral asalariada en el sistema de seguridad social ${ }^{1}$.

Si bien la existencia del empleo informal es el resultado de un complejo entramado de actores y de circunstancias, tanto los empleadores como los trabajadores y la autoridad pública a cargo del control del cumplimiento de la normativa laboral y de la seguridad social, juegan un rol central en el surgimiento de este fenómeno ${ }^{2}$. La contratación de empleados en el sector público está sujeta al nivel de recursos destinados al presupuesto nacional. En general, la Ley marco de regulación del empleo público

1 El sistema de seguridad social en Argentina está compuesto por los siguientes seis componentes, el régimen previsional; las obras sociales; el seguro de desempleo; sistema de riesgos del trabajo; el Plan de Asistencia Médica Integral (PAMI) que brinda cobertura médica a la tercera edad; y el régimen de asignaciones familiares, que otorga subsidios múltiple. Por otra parte, la seguridad social se diferencia del resto de la política social por su carácter contributivo. Es decir que para acceder a las prestaciones, la persona debe contar con aportes y contribuciones sobre la nómina salarial (Ronconi, 2001). De modo que si el trabajador se encuentra registrado en el sistema de seguridad social puede acceder a todos los beneficios que brinda este sistema. Por ello, la evidencia indica una elevada correlación entre la ausencia de registro y los otros beneficios del sistema de seguridad social.

2 Otros actores que podrían tener un potencial interés al respecto son los sindicatos (Ronconi, 2001). 
de 1999 permite tres regímenes de empleo público: el de estabilidad, el de contrataciones por tiempo determinado y el de prestación de servicios al personal de gabinete de las autoridades superiores ${ }^{3}$ (Pomares et al. 2013). Esta misma ley enumera los derechos de los trabajadores del estado según cada régimen de contratación: entre ellos se destaca el acceso a una jubilación. El goce de este derecho queda sujeto al registro de los empleados estatales en el sistema de seguridad social. Dado que es el mismo estado quien realiza la contratación, generalmente, se asume que el empleador estatal cumple con la normativa laboral y de la seguridad social al momento de celebrar un contrato de trabajo. Sin embargo, se constata la presencia de trabajadores informales en este sector. Los incentivos para la contratación de empleo informal por parte del estado podrían responder, en parte, al ahorro o malversación de los recursos públicos como al sistema de coparticipación vigente entre el estado nacional y las provincias. Así por ejemplo, en Argentina, los tributos a la seguridad social son de carácter federal y no-coparticipable, lo cual significa que los montos recaudados tienen como destino exclusivo al gobierno nacional (Ronconi, 2001). Esto último podría favorecer la aparición de empleo informal aun tratándose de las mismas autoridades públicas. Por eso, el "estado nacional no solo debe realizar un esfuerzo para la unificación de los marcos normativos que regulan la organización del trabajo y su gestión, sino también para incrementar su alcance y cobertura en todos los niveles del gobierno" (Pomares et al., 2013, p. 20) .

En el caso del sector privado, la teoría económica asume que el comportamiento de estos individuos está sujeto a la búsqueda de sus objetivos. Así, mientras el trabajador busca obtener el mayor nivel de ingreso y seguridad por cada nivel de esfuerzo, el empleador tiene como motivación principal, la búsqueda de ganancias. En este contexto, el empleador y el trabajador, podrían tener incentivos contrapuestos respecto a si declarar o no la relación laboral. Mientras el empleado, generalmente, espera que su empleador cumpla con la normativa laboral y de la seguridad social, el empleador puede

3 El régimen de estabilidad comprende "al personal que ingrese por los mecanismos de selección que se establezcan, a cargos pertenecientes al régimen de carrera cuya financiación será prevista para cada jurisdicción u organismos descentralizados en la Ley de Presupuesto. El régimen de contrataciones por tiempo determinado comprende a la prestación de servicios de carácter transitorio o estacional, que no puedan ser cubiertos por el personal de planta permanente bajo régimen de estabilidad. Incluye al personal comúnmente denominado de planta transitoria. El porcentaje de personal bajo este régimen no puede superar el porcentaje estipulado en el convenio colectivo de trabajo, que se vincula con el número de empleados en planta permanente. Por último, está el régimen de prestación de servicios del personal de gabinete de las autoridades superiores, que solo comprende a las funciones de asesoramiento o asistencia administrativa. El personal bajo este régimen cesa en sus funciones al mismo tiempo que la autoridad cuyo gabinete integra y su designación puede ser cancelada en cualquier momento". (Pomares et al., 2013, pp. 7-8).

4 "Pues aún prevalece una normativa fragmentaria y heterogénea que dificulta la organización y gestión del empleo: existen seis regímenes jurídicos y siete escalafones que regulan el empleo público en el sector público nacional no financiero que incluye al Poder Ejecutivo Nacional, las empresas y sociedades del Estado nacional y otros entes del sector público nacional tales como el ente recaudador de impuestos (la AFIP) y otros" (Pomares et al., 2013, p. 5). 
optar por no declarar la relación laboral (Ronconi, 2001). Esta opción está basada en cálculos racionales de maximización de ganancias que, a su vez, dependen de los costes y beneficios derivados de la contratación de empleo informal. Así, las empresas escogen su nivel óptimo de adhesión a las reglas institucionales y laborales, dependiendo de la evaluación de los beneficios netos relacionados con el cumplimiento de las normativas laborales y del esfuerzo y capacidad de fiscalización del Estado (Perry et al., 2007). Dentro del conjunto de beneficios, se encuentran, por un lado, los indirectos que surgen por el ahorro del tiempo y de los recursos destinados a los procedimientos administrativos, frecuentemente complejos, asociados con decisiones sobre empleo, despidos, salarios y horas de trabajo. Por otro lado, se encuentran los beneficios directos que están asociados con la reducción o eliminación de los pagos de impuestos y de contribuciones a la seguridad social ${ }^{5}$. Sin embargo, la informalidad laboral puede generar consecuencias negativas para el trabajador y la sociedad, como para la economía en general. Desde el punto de vista del bienestar individual, los trabajadores que no están protegidos bajo el sistema de seguridad social, no pueden, en general, evitar los efectos negativos que causan la enfermedad, la discapacidad, el desempleo o la pérdida del ingreso en la vejez. Desde una perspectiva socioeconómica, las fallas del sistema de seguridad social para cubrir a los trabajadores informales frente a shocks adversos en la salud o en el ingreso, producen pérdidas individuales e imponen costes externos a la sociedad. Desde el punto de vista de las empresas, la informalidad laboral puede generar un incremento potencial de los ingresos y una mayor competitividad vía precios. Pero, para las empresas que no son evasoras, esto último supone enfrentar una competencia desleal que puede conllevar a pérdidas de productividad (Perry et al., 2007).

No obstante, la contratación de empleo informal también puede generar una serie de costes directos e indirectos para las empresas evasoras. Los costes indirectos se producen porque una relación laboral sin un contrato debidamente registrado elimina, o por lo menos reduce mucho, el acceso a los tribunales y a otros mecanismos formales para su cumplimiento. También puede dificultar el acceso al crédito, a mercados más grandes, a fuentes de innovación, a la producción en un tamańo de escala óptima generando impactos negativos sobre los niveles de productividad (Perry et al., 2007). Los costes directos, por su parte, están asociados con el pago de multas o incluso la clausura de las empresas evasoras. Sin embargo, para que este coste sea efectivo, las empresas deben ser detectadas por las autoridades encargadas de la fiscalización. Dado que para el Estado es ineficiente o imposible el control del cumplimiento de la normativa laboral y de la seguridad social empresa por empresa, la inspección tiende a concentrarse en las empresas medianas y grandes. Pero incluso aunque estas sean detectadas, existe la posibilidad de que los

\footnotetext{
5 En Argentina la seguridad social se financia principalmente a través de aportes y contribuciones sobre la nómina salarial. Según los datos del Ministerio de Trabajo, Empleo y Seguridad Social, dichos tributos ascienden en promedio al 22\% del salario durante 1995-2014.
} 
empresarios eviten las multas o la clausura mediante pago de soborno a los inspectores. Por ello, se espera que en países donde los niveles de corrupción son más altos, como en Argentina ${ }^{6}$, las empresas tengan mayores probabilidades de evadir el pago de impuestos y las contribuciones a la seguridad social (Perry et al., 2007). Esto último podría cambiar la relación de costes y beneficios derivados de la contratación de empleo informal. Pues, si se reducen los costes directos (ya sea porque la intensidad con que se hacen cumplir las regulaciones o la probabilidad de ser detectadas son bajas o bien existe la posibilidad del pago de sobornos para evitar multas) en relación con los beneficios (baja calidad o valor de los servicios provistos por el mercado o por el gobierno), más incentivos tienen las empresas para contratar empleo informal (Perry et al., 2007). De modo que no solo importa la cantidad, sino la calidad de las instituciones y reglamentaciones laborales. $\mathrm{Y}$ en este aspecto, la autoridad pública ${ }^{7}$ también juega un rol fundamental en el balance de estos costes y beneficios, principalmente entre las empresas más grandes.

En Argentina, las facultades y atribuciones referidas a la inspección de trabajo y al control del cumplimiento de la seguridad social están descentralizadas en las provincias, los tributos a la seguridad son de carácter federal y no-coparticipable, lo cual significa que los montos recaudados tienen como destino exclusivo al gobierno nacional (Ronconi, 2001). En este contexto, los gobiernos provinciales podrían tener los mismos incentivos que las empresas por contratar empleo informal, ya que se enfrentan a una situación en la cual no obtienen los beneficios por el cumplimiento del empleo formal por parte de las empresas, mientras que los costes de la fiscalización son significativos (Ronconi, 2001). La presencia de trabajadores informales dentro del sector público y de un mercado de trabajo altamente visible por parte de los organismos de control además de inquietante, requiere un análisis más detenido. Por ello, este artículo centra su análisis en el mercado de trabajo de las empresas de mediano y de gran tamaño (unidades productivas que contratan más de seis empleados) así como del sector público (MGEySP).

A pesar de la importancia del empleo informal, este no es el único fenómeno característico del mercado de trabajo argentino. La modificación de los regímenes de contratación laboral en la década de 1990 favoreció la aparición de empleos de agencia ${ }^{8}$,

\footnotetext{
${ }^{6}$ En estos casos, los niveles de corrupción en un país pueden también jugar un papel importante en la determinación de los incentivos de las empresas para emplear trabajadores informales. Según la Organización internacional de transparencia internacional, Argentina incrementó su posición en el ranking de corrupción de forma sostenida durante 1995-2014.

7 La presencia de este fenómeno muchas veces pone en descubierto la existencia de instituciones débiles y de fallas regulatorias gubernamentales.

8 El empleo de agencia tiene lugar cuando un trabajador es empleado por la agencia de empleo temporal y contratado para realizar su trabajo en la empresa usuaria (y bajo la supervisión de la misma). Se considera que no existe una relación de trabajo entre el trabajador temporal cedido por la agencia y la empresa usuaria, aunque la empresa usuaria podría tener obligaciones legales hacia dicho trabajador, en particular con respecto a la seguridad y la salud (Artículo 1 del Convenio sobre las agencias de empleo privadas, 1997, núm. 181).
} 
a tiempo parcial, temporales y económicamente vulnerables (Rodgers, 1989 y Heckman y Pagés, 2005). En Argentina este tipo de empleos se introdujo mediante modificaciones en los esquemas de contratación laboral, siguiendo la lógica de que la flexibilización de las relaciones de trabajo mejoraría la competitividad. No obstante, al ingresar en el nuevo siglo, se dio marcha atrás con las reformas flexibilizadoras de la década anterior, tanto en lo que se refiere a la legislación de protección social, como a las reducciones generales de las contribuciones patronales (Betranou et al., 2014). Esto ha dado lugar a que el país experimente una profunda transformación en su estructura del empleo entre la década de 1990 y los años 2000. En consecuencia, las condiciones de empleo en Argentina deben ser evaluadas desde un enfoque más amplio que el de la informalidad laboral. Por ello, en este artículo se entiende que la calidad del empleo engloba, en cuatro dimensiones prioritarias, distintos aspectos del trabajo, no solo los referentes a la protección social, sino también a los derechos laborales, a las oportunidades de empleo y al diálogo social (OIT, 2002) ${ }^{9}$. Atendiendo a este concepto, se investiga la presencia en las MGEySP de otros déficits en atributos de la calidad del empleo más allá del referente a la formalidad laboral (tales como la jornada de trabajo, la estabilidad laboral y la satisfacción con el empleo). Con relación a esto se considera que los cambios ocurridos en los regímenes laborales desde mediados de los noventa pueden haber modificado las condiciones de empleo, incluso en las MGEySP.

Las distintas condiciones de empleo pueden producir consecuencias sobre la estructura del mercado laboral. Por ello, se evalúa si la heterogeneidad laboral potencialmente existente en las MGEySP, durante 1995-2014, puede estar asociada a una segmentación laboral. Las consecuencias de las condiciones laborales heterogéneas para la estructura del mercado de trabajo ha sido centro de un intenso debate en la literatura teórica. La discusión gira en torno a dos hipótesis teóricas contrapuestas. Una de ellas, denominada hipótesis de segmentación laboral, considera que la existencia de empleos de distinta calidad produce la división del mercado de trabajo en diferentes segmentos (Harris y Todaro, 1970; Doeringer y Piore, 1971; entre otros). Como resultado de esto existirán trabajadores que, a pesar de poseer los atributos personales requeridos para ocupar un puesto de mayor calidad, no tienen acceso a este puesto y por tanto, reciben un salario inferior al que les correspondería. Por ello es que, una de las formas en que se manifiesta un mercado de trabajo segmentado es a través de brechas salariales entre trabajadores de similares características productivas que pertenecen a distintos segmentos. Asimismo debe comprobarse que dichos diferenciales de ingreso se corresponden con una baja movilidad laboral que impide que los trabajadores se desplacen libremente al segmento óptimo de ocupación dados sus atributos personales. La teoría opuesta a la de segmentación es la denominada hipótesis de voluntariedad del empleo informal, cuyo

\footnotetext{
9 Esta definición se corresponde con el concepto de trabajo decente que introdujo la Organización Internacional del Trabajo (OIT).
} 
principal exponente es Maloney $(1999,2004)$. Este enfoque considera un modelo de mercado laboral competitivo y sin segmentación en el que los trabajadores pueden elegir voluntariamente el segmento de ocupación en función de la utilidad que les reporta un conjunto de atributos salariales y no salariales del puesto de trabajo elegido. Las teorías más recientes combinan los dos puntos de vista polares de la teoría de segmentación y la de voluntariedad del empleo informal (Fields, 2005 y Günther y Launov, 2006). Así pues, sostienen que el mercado de trabajo presenta una estructura compleja con un segmento de empleos de buena calidad y otro segmento de puestos de mala calidad compuesto de trabajadores que ingresan voluntariamente así como de ocupados que han sido expulsados del segmento de buenos empleos.

Conforme con lo expuesto previamente, el objetivo central de este artículo consiste en investigar si la heterogeneidad laboral presente en las MGEySP, durante 1995-2014 ${ }^{10}$, pudo haber generado una segmentación más compleja que la relacionada con la existencia de trabajadores formales e informales. Esto último implica cuestionar varios estudios disponibles ${ }^{11}$ para Argentina que enfatizan que la segmentación laboral se produce exclusivamente como consecuencia del empleo informal o dentro del sector informal. En este último caso, las investigaciones empíricas exploran si dentro de este sector existen dos segmentos uno correspondiente a los empleados que se encuentra voluntariamente ocupados como informales y otro segmento compuesto por los empleados que fueron excluidos de los puestos de trabajo en el sector formal (Gasparini y Tornarolli, 2007; Banco Mundial y MTEySS, 2008; Günther y Launov, 2008; Loayza y Rigolini, 2012; entre otros). Con ello se pretende enriquecer la discusión actual sobre la segmentación del mercado laboral en Argentina explorando la presencia de segmentos particulares en las MGEySP, más allá de los que surgen de la mera clasificación de los trabajadores en formales e informales. En este sentido, se espera que los resultados de esta investigación permitan descubrir algunas particularidades poco conocidas del mercado de trabajo de las MGEySP, así como revelar ciertos hechos estilizados que pudieron haber permanecido ocultos dados los supuestos realizados por la literatura.

El artículo está estructurado de la siguiente manera. En la siguiente sección, se presentan los principales antecedentes a este estudio. En la tercera sección se describe los datos utilizados en el análisis empírico. Paso seguido se enuncian las hipótesis de seg-

${ }^{10}$ En Jiménez (2013) se constata que durante la segunda mitad de los noventa y, en menor medida, en los dos mil, una incidencia relativamente elevada de la informalidad laboral en las MGEySP que se presenta como un fenómeno que no es exclusivo de las pequeñas empresas (que suelen incluirse en el sector informal). Pero más allá de la informalidad laboral existen importantes déficits en otras dimensiones de la calidad del empleo referentes a la jornada de trabajo, la estabilidad laboral y la satisfacción con el empleo. Estos déficits existen tanto dentro del empleo asalariado formal como del empleo informal, pero en mayor magnitud en el primero que en el segundo.

${ }_{11}$ Los antecedentes empíricos previos a esta investigación han medido la incidencia de este fenómeno en las MGEySP sin analizar otras condiciones laborales relacionadas con la calidad del empleo (MTEySS y BM, 2008; MTEySS, 2014; entre otros). 
mentación laboral para el empleo asalariado en las MGEySP. En la quinta sección se presenta la metodología utilizada para estimar brechas salariales, su descomposición en el tiempo y patrones de movilidad para evaluar las hipótesis de segmentación laboral formuladas. En la sexta sección se describen los resultados obtenidos y en la última sección se presenta las principales conclusiones del artículo.

\section{REVISIÓN DE LA LITERATURA}

Entre los primeros aportes empíricos de la literatura sobre segmentación laboral se destacan los realizados por McDonald y Solow (1985), Dickens y Lang (1993), Bernhardt (1994) y Maloney (1999). Estas investigaciones dieron lugar al desarrollo de una serie de estudios que se caracterizan por analizar la segmentación laboral desde un enfoque dual que supone la presencia de al menos dos segmentos en el mercado de trabajo: el de los buenos empleos y el de los malos empleos. No obstante, la definición de buenos y malos empleos puso su acento en diferentes características del empleo en los países en desarrollo que en los desarrollados. Mientras en los primeros, la falta de registro de la relación laboral es propia de los malos empleos, en los países desarrollados, estos últimos se encuentran asociados con los contratos de trabajo temporarios. Entre las investigaciones más recientes que forman parte de este último grupo se encuentra la de Hirsch (2016) quien señala que los trabajos permanentes y temporarios son la principal causa de la dualidad en el mercado laboral de Alemania. A esta misma conclusión arriba Deakin (2013), en el caso de Portugal y España, luego de un exhaustivo análisis de la literatura empírica para algunos países europeos. Asimismo, Svalund (2013) indica que en los países con regulación laboral flexible, como Dinamarca, existe una mayor transición desde los empleos temporarios a los permanentes. Pero, en Finlandia y Suiza sucede lo contrario.

Entre las investigaciones recientes para países en desarrollo se encuentra la de Alcaraz et al. (2015) quien comprueba que la informalidad laboral causó una segmentación en el mercado de trabajo mexicano. No obstante existe una importante proporción de trabajadores informales que se autoselecciona al sector informal. Por el contrario, Sharma (2013) cuestiona la frecuente creencia de que el mercado laboral en Indonesia está segmentado a causa de las instituciones legales (salario mínimo, beneficios obligatorios y sindicatos). Sus resultados sugieren que un buen porcentaje de la brecha salarial entre el empleo formal e informal es explicada por la heterogeneidad individual y el tamaño de la empresa. Kumas et al. (2014), por su parte, encuentran, en el mercado de trabajo de Turquía, una estructura estratificada por género, educación, estado civil, calificación de la tarea y tipo de ocupación.

En América Latina los estudios que analizan la estructura del mercado de trabajo son crecientes pero la evidencia empírica que aportan es contradictoria. La hipótesis comúnmente estudiada consiste en suponer que la informalidad produce la división del mercado de trabajo en dos segmentos: el formado por el sector formal y el compuesto 
por el sector informal. Entre los estudios empíricos que forman parte de este enfoque se encuentra el desarrollado por Waisgrais (2001) en Argentina para el período 1997-2003. Los resultados señalan que la transición desde la informalidad hacia la formalidad está asociada a cambios positivos en el salario real, mientras que quienes realizan la transición inversa presentan reducciones salariales que promedian el 35\%. La evidencia obtenida por Beccaria, Groisman y Monsalvo (2006) para la Argentina durante el período 1993-2005 indica que el valor medio de la brecha salarial para todos los trabajadores informales asciende al 45\% del ingreso horario formal si se la estima por mínimos cuadrados ordinarios (MCO) y desciende levemente al $41 \%$ si la estimación se lleva a cabo con regresiones cuantílicas. A partir de este último estudio, Maurizio (2012) desarrolla un análisis similar para cuatro países de Latinoamérica (Argentina, Brasil, Chile y Perú) y comprueba que la informalidad laboral es una fuente independiente de bajos ingresos incluso después de controlar por un vector amplio de características personales y laborales, lo que implica la existencia de segmentación laboral de la forma predicha en todos los países considerados. Casal y Barham (2013), por su parte, exploran si las licencias por maternidad están asociadas con la segmentación del mercado de trabajo en un sector formal y otro informal. La evidencia obtenida apoya esta hipótesis.

Un enfoque opuesto al anterior considera que la informalidad laboral es una elección voluntaria por parte del trabajador dado que los trabajadores obtienen una compensación no pecuniaria por la pérdida de beneficios de la seguridad social. Dentro de este grupo se encuentran las investigaciones empíricas de Pratap y Quintín (2006) para el período 1993-1995 y la de Bosch y Maloney (2010) para el período 1993-2001. Los resultados obtenidos del primer estudio indican que las transiciones de una buena parte de los trabajadores que pertenecen al sector informal son consistentes con la visión voluntaria. Pero los desplazamientos del empleo asalariado informal son más consistentes con la visión de segmentación, particularmente entre los trabajadores asalariados más jóvenes. Pratap y Quintín (2006), en cambio, señalan que la hipótesis de mercados laborales competitivos en Argentina no puede ser rechazada pues los trabajadores informales se encuentran mejor en dichos puestos de trabajo, los que a su vez, son preferidos a los empleos formales.

El resto de la literatura empírica para Argentina analiza si la presencia de un segmento formal y otro informal en el mercado de trabajo puede responder a un modelo competitivo (como propone la hipótesis de voluntariedad del empleo informal) o a uno segmentado. Entre estos estudios se encuentra el de Alzúa (2008) que asume que el mercado laboral global en el Gran Buenos Aires (GBA) se ha comportado diferente a lo largo del período 1975-2001 siendo competitivo durante 1975-1991 y segmentado en 1992-2001. No obstante, la evidencia no apoya esta hipótesis. Arias y Khamis (2008), por su parte, encuentran que la hipótesis de voluntariedad del empleo informal se cumple para los trabajadores independientes pues no existen diferencias salariales estadísticamente significativas entre ellos y los empleados formales. Pero existe evidencia 
a favor de la visión de segmentación cuando se comparan los ingresos laborales de los empleados formales e informales.

Otro grupo de estudios empíricos adoptan el enfoque integrador, ya mencionado en el marco teórico de la sección anterior, que concilia las dos posiciones antagónicas de las teorías de segmentación y la de voluntariedad del empleo informal. El análisis está basado en los modelos teóricos de mercado laboral en el que coexisten un sector formal y un sector informal heterogéneo compuesto por más de un segmento (Martínez Soria, 2008; Fields, 2011). Esta hipótesis ha sido contrastada por Günther y Launov (2006, 2011) quienes definen con mucha claridad el planteamiento multisectorial. Estos autores implementan un enfoque econométrico conocido como modelo mixto finito (FMM) que permite comprobar la existencia de un número finito de segmentos en el sector informal de Côte d'Ivore cuando no es posible observar la afiliación de los individuos a cada uno de los potenciales subsectores que lo constituyen. Esta metodología fue implementada para Egipto por Harati (2013) y para Turquía por Ben Salem et al. (2011) quienes encontraron que el mercado laboral de esos países está formado por un sector formal y otro informal dentro del cual coexisten dos segmentos distintos.

Por otra parte, se destaca que en varios estudios propios anteriores se comenzaron a explorar algunas de las hipótesis de mercado laborales multisegmentados (Jiménez y Jiménez, 2009, Jiménez, 2011; 2013; Bertranou et al., 2014). Entre estos se encuentra el de Bertranou et al. (2014) que constituye uno de los antecedentes más directos de este artículo. Los autores examinan distintas hipótesis de segmentación para todo el mercado de trabajo argentino y su relación con los cambios ocurridos durante 1995-2011. Los resultados obtenidos sugieren que la existencia de una estructura segmentada en el mercado de trabajo argentino se encuentra principalmente asociada con el fenómeno de la informalidad laboral y no con la modalidad de contratación laboral.

Por tanto, el análisis desarrollado en este artículo difiere de la literatura empírica existente en dos aspectos centrales. Primero, la mayoría de los estudios mencionados considera que la potencial segmentación del mercado de trabajo está asociada exclusivamente a la duración del contrato de trabajo o a la informalidad laboral. En segundo lugar, los estudios empíricos para Argentina que identifican a las MGEySP con el sector formal de la economía, suelen asumir a priori e implícita o explícitamente, que este es un mercado homogéneo respecto a las condiciones laborales que ofrece y por tanto, no presenta una estructura segmentada. En este artículo, en cambio, se levanta ambos supuestos. Por un lado se analiza la existencia de empleos de distinta calidad en las MGEySP más allá de los que surgen de considerar la duración del contrato laboral o el registro en el sistema de seguridad social. Por otro lado, se explora si la existencia de empleos de distinta calidad está asociada a múltiples segmentos dentro del mercado de las MGEySP produciendo una estructura compleja que requiere ser analizada mediante distintas hipótesis de segmentación para determinar la existencia de segmentos diferentes a los estudiados en la literatura empírica hasta el momento. 


\section{DESCRIPCIÓN DE LOS DATOS}

El análisis empírico presentado en esta investigación está basado en los microdatos provenientes de la Encuesta Permanente de Hogares (EPH) para el período 1995-2014. Así, la EPH incluye un relevamiento específico sobre el mercado de trabajo conforme a estándares internacionales, con el fin de garantizar cierta comparabilidad. Además de las tasas de actividad, empleo y desempleo, la EPH permite conocer el porcentaje de empleo informal a partir de las declaraciones que realizan los trabajadores asalariados sobre sus contribuciones a la seguridad social (Bertranou et al., 2011; Bertranou et al., 2013). Por esto, constituye la principal fuente de datos sobre variables que caracterizan el funcionamiento del mercado de trabajo. Esta información es recolectada en los principales centros urbanos del país que son capitales de provincias (excepto San Nicolás).

Durante el período de análisis la EPH tiene dos modalidades distintas de captación de la información, una puntual (EPHP de mayo de 1995 a mayo de 2003) y otra continua (EPHC del segundo trimestre de 2003 al cuarto trimestre de 2014 ${ }^{12}$ ). Por ello, se implementaron en esta investigación una serie de criterios de armonización con la EPHP propuestos por Roca et al. (2006) que se presentan en el Cuadro A1.

El análisis empírico de este estudio se desarrolla para el grupo de asalariados de 15 a 64 ańos que se encuentran empleados en las medianas y grandes empresas (unidades productivas que contratan a más de 6 empleados) y el sector público que no son beneficiarios de planes de empleo otorgados por el Estado argentino ${ }^{13}$. A fin de comprobar empíricamente las hipótesis de segmentación formuladas se estiman diferencias salariales y patrones de movilidad laboral. Los datos utilizados surgen de unir la información sobre los individuos entrevistados dado que la muestra de la EPH es parcialmente rotativa $^{14}$. El porcentaje de atrittion (es decir, de desgranamiento o pérdida de observaciones debido a la no respuesta) no supera el $10 \%$ en ninguna de las bases de datos longitudinales construidas. El Cuadro A2 presenta la cantidad de observaciones en cada base de datos.

\footnotetext{
12 Esta es la última base de microdatos de la EPH disponible al momento de la elaboración del presente artículo.

${ }^{13}$ La muestra se restringe a la edad de 15 a 64 años para desarrollar al análisis para toda la población en edad de trabajar. Los beneficiarios de planes de empleo se excluyen para evitar una posible sobreestimación de la población ocupada pues estos asalariados suelen considerarse dentro del grupo de individuos con desempleo oculto.

${ }^{14}$ La renovación de la muestra de dicha encuesta se denomina esquema de rotación descripto detalladamente en INDEC (2003).
} 


\section{PLANTEO DE HIPÓTESIS}

Dado que se constata una incidencia relativamente elevada de la informalidad laboral en las MGEySP durante todo el período analizado, la primera hipótesis a contrastar es la segmentación entre empleos asalariados formales (AF) e informales (AI).

En segundo lugar, la evidencia obtenida indica que existen importantes déficits en otros atributos de la calidad del empleo, tanto en el conjunto de asalariados de las MGEySP, como dentro del empleo formal e informal. Por esto, se clasifican a estos asalariados en cuatro categorías laborales, no definidas aún en la literatura empírica hasta el momento, considerando las combinaciones posibles entre la condición de (in)formalidad laboral de los trabajadores y la presencia de déficit en otros atributos que definen la calidad del empleo. Así se distingue entre:

i) Asalariados formales con déficits en otros atributos de la calidad del empleo (AFCD): empleados en relación de dependencia que celebran contratos laborales registrados en el sistema de seguridad social o que poseen cotización en el sistema previsional pero declaran encontrarse en algunas de las siguientes situaciones. Están ocupados en un puesto de trabajo inestable (que tiene un período de finalización), son empleados a tiempo parcial en forma involuntaria (trabajan menos de 32 horas semanales y desean trabajar más) o están sobreocupados (trabajan más de 48 horas semanales) o bien declaran estar insatisfechos con su empleo (están en la búsqueda de otra ocupación o desean o buscan más horas de trabajo).

ii) Asalariados informales con déficits en otros atributos de la calidad del empleo (AICD): empleados en relación de dependencia que no celebran contratos laborales registrados en el sistema de seguridad social o no poseen cotización en el sistema previsional y además declaran estar ocupados en un puesto de trabajo con período de finalización, encontrarse en empleos a tiempo parcial en forma involuntaria o sobreocupados o bien insatisfechos con sus empleos. Este grupo de trabajadores ocupan los peores puestos de trabajo en términos de calidad pues presentan déficits en todos los atributos de la calidad del empleo considerados.

iii) Asalariados informales sin otro déficit en la calidad del empleo (AISD): empleados en relación de dependencia que no tienen contratos laborales registrados en el sistema de seguridad social o cotización al sistema previsional pero declaran estar ocupados a tiempo indefinido (es decir, sin período de finalización), en trabajos de plena ocupación (trabajan 48 horas semanales) o que tienen satisfacción laboral (no se encuentran en la búsqueda de otro empleo o no desean ni buscan más horas de trabajo).

iv) Asalariados formales sin ningún déficit en la calidad del empleo (AFSD) o asalariados con puestos de trabajo de calidad: empleados en relación de dependencia que 
declaran celebrar contratos registrados en el sistema de seguridad social o con cotización en el sistema previsional y además tienen contratos a tiempo indefinido, se encuentran en plena ocupación y reportan satisfacción laboral. Este grupo de trabajadores ocupan los mejores puestos de trabajo en términos de calidad pues no presentan ningún déficit en la calidad del empleo.

\section{Diagrama}

Hipótesis de segmentación laboral para el mercado de trabajo de las MGEySP

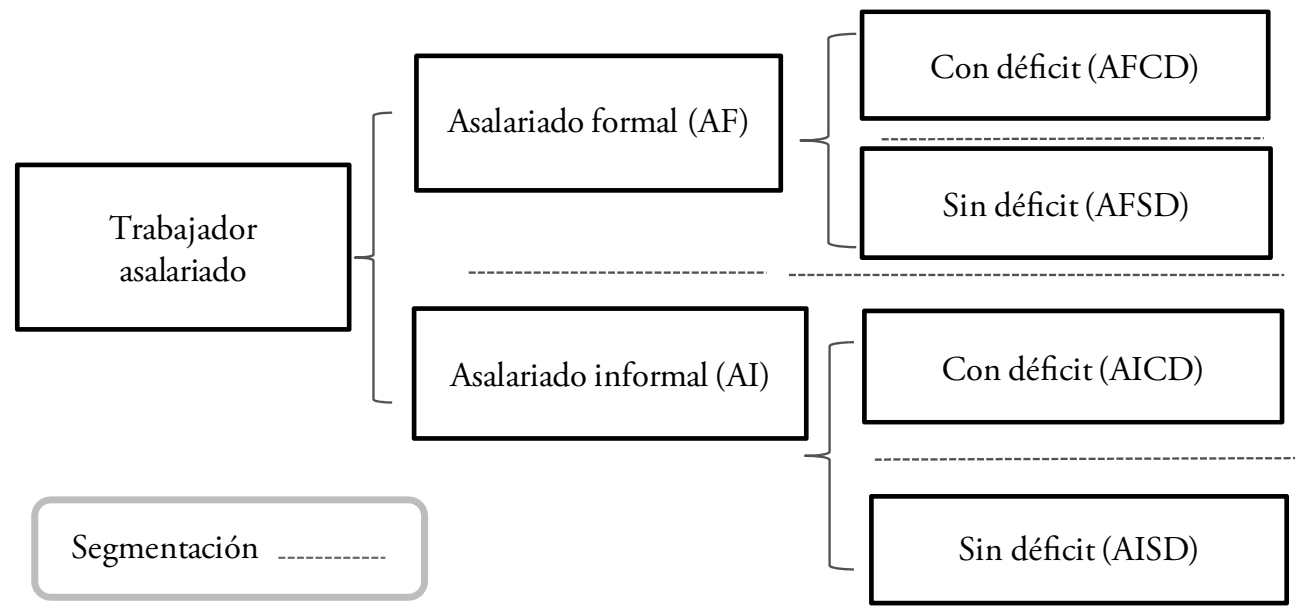

Fuente: elaboración propia sobre la base de Bertranou et al. (2014).

A partir de las categorías laborales definidas previamente es posible formular otras hipótesis de segmentación. Una de ellas considera cuatros segmentos, dos dentro de los puestos asalariados informales compuestos por los AICD y los AISD y otros dos dentro de los empleos formales constituidos por los AFCD y los AFSD. La hipótesis alternativa a esta supone que la segmentación laboral se produce entre el puesto de trabajo de mejor calidad, es decir, un empleo formal sin ningún déficit (AFSD) y el resto de los asalariados (RA) de las MGEySP. De igual manera, se puede asumir también que la segmentación laboral tiene lugar entre el puesto de trabajo de peor calidad, es decir, el de los AICD y el resto de los asalariados (RA). Por último, otras hipótesis consideran la presencia de tres segmentos. En primer lugar, se evalúa la presencia de dos segmentos dentro de los AI (AICD y AISD) y un tercero que incluye a los asalariados formales. En este caso se asume que los déficits dentro de los AI pueden ser más relevantes que entre los AF. O alternativamente, podrían existir dos segmentos dentro de los AF (AFSD y AFCD) y otro compuesto por los AI. Esta hipótesis se sustenta en la evidencia anterior que muestra que el grupo de los AF es de mayor tamaño que el de los AI y además, que los AFCD superan a los AFSD durante gran parte del período. 
En el Gráfico 1 se presenta la composición del empleo asalariado en las MGEySP según las cuatro categorías laborales previamente definidas. Puede observarse que durante la segunda mitad de la década de 1990 hasta 2005, la participación de los AFCD supera significativamente la de los AFSD, pero a partir del año siguiente, el empleo AFSD es el puesto de trabajo más frecuente en este mercado. El porcentaje de AFSD presenta una tendencia creciente entre 2004 y 2014 (del 35\% a casi el 50\%), ocurriendo lo contrario con el porcentaje de AFCD que se redujo del $42 \%$ al 34\% durante esos ańos. Además, la participación del empleo formal supera ampliamente la de los asalariados informales.

Por otra parte, dentro del empleo informal el tipo de inserción laboral más frecuente, durante todo el período es la que presenta déficit de calidad, superando los AICD a los AISD en 12 puntos porcentuales en promedio. También se aprecia que mientras el porcentaje de los AISD permanece relativamente estable durante todo el período, el de los AICD fue variable. Así, se incrementa en la década de 1990 y desciende durante los últimos ańos, partiendo del 19\% en 2004 al 11\% en 2014 .

Los resultados previos indican, por un lado, que la mayoría de los asalariados en las MGEySP (entre el 50\% y el 70\%) presentan déficit en alguna dimensión de la calidad del empleo.

El Gráfico 1 también sugiere que esta composición del empleo está asociada con las fases del ciclo económico y los esquemas vigentes de las instituciones laborales. Así, las MGEySP parecen reducir los costes de contratación laboral durante los períodos de caída de la actividad económica, mediante una combinación de modalidades contractuales atípicas permitidas por ley (particularmente, durante la flexibilización laboral introducida en los noventa) y el incumplimiento de la legislación laboral. Luego, en las fases más dinámicas del ciclo, las MGEySP parecen optar más por mejorar las condiciones de empleo dentro de los AF que por reducir los empleos sin registro en la seguridad social. Justamente, durante 2003-2014, la participación de los AFSD aumenta 16 puntos porcentuales mientras la de los AI cae cerca de 8 puntos porcentuales. La diferente evolución y magnitud que presentan los porcentajes de cada una de las categorías laborales analizadas podría estar asociada con una segmentación laboral particular durante los noventa y otra en los dos mil.

Por otra parte, el análisis de las características personales y laborales de cada grupo de asalariados revela que las cuatro categorías de empleo en las MGEySP constituyen, en casi todos los años del período analizado, una modalidad de inserción laboral mayoritariamente masculina (Cuadro A3 a A6). En promedio, durante 1995-2003, el 50\% de los AFSD, el 70\% de los AFCD, el 68\% de los AICD y el 54\% de los AISD son varones. No obstante, durante 1995-2014, el porcentaje de varones presentes entre los AFCD y AICD supera al de los AFSD y AISD.

Cuando se analiza la composición por edad de este conjunto de asalariados puede observarse que los adultos de edad central (30 a 49 años) concentran la mayor parte 
del empleo formal en las MGEySP. Más del 50\% entre los AFSD y más del 53\% entre los AFCD pertenecen a ese grupo etario. En cambio, los jóvenes tienen una mayor participación en los puestos asalariados informales que en las formales. No obstante, la proporción de jóvenes es similar a la de adultos entre los AISD desde los dos mil y entre los AICD desde 2009.

Respecto al nivel educativo se aprecia que los asalariados que lograron completar el nivel secundario pero no el universitario tienen una participación relativamente similar en los grupos examinados. No obstante, a diferencia del resto, entre los AFSD, el porcentaje de empleados con un nivel universitario completo crece más rápidamente durante todo el período, disminuyendo así la participación de los que tenían un nivel educativo bajo. De forma tal que, a partir de 2003, la proporción de AFSD con nivel educativo medio y alto son relativamente similares. Además, el porcentaje de AFSD con universitario completo supera ampliamente al del resto de los grupos. Por otra parte, la participación de empleados con nivel educativo bajo es significativamente mayor entre los AICD en comparación con los otros asalariados. Sin embargo, se reduce durante 1995-2014.

Gráfico 1. Composición del empleo asalariado por calidad del empleo en las MGEySP, 1995-2014

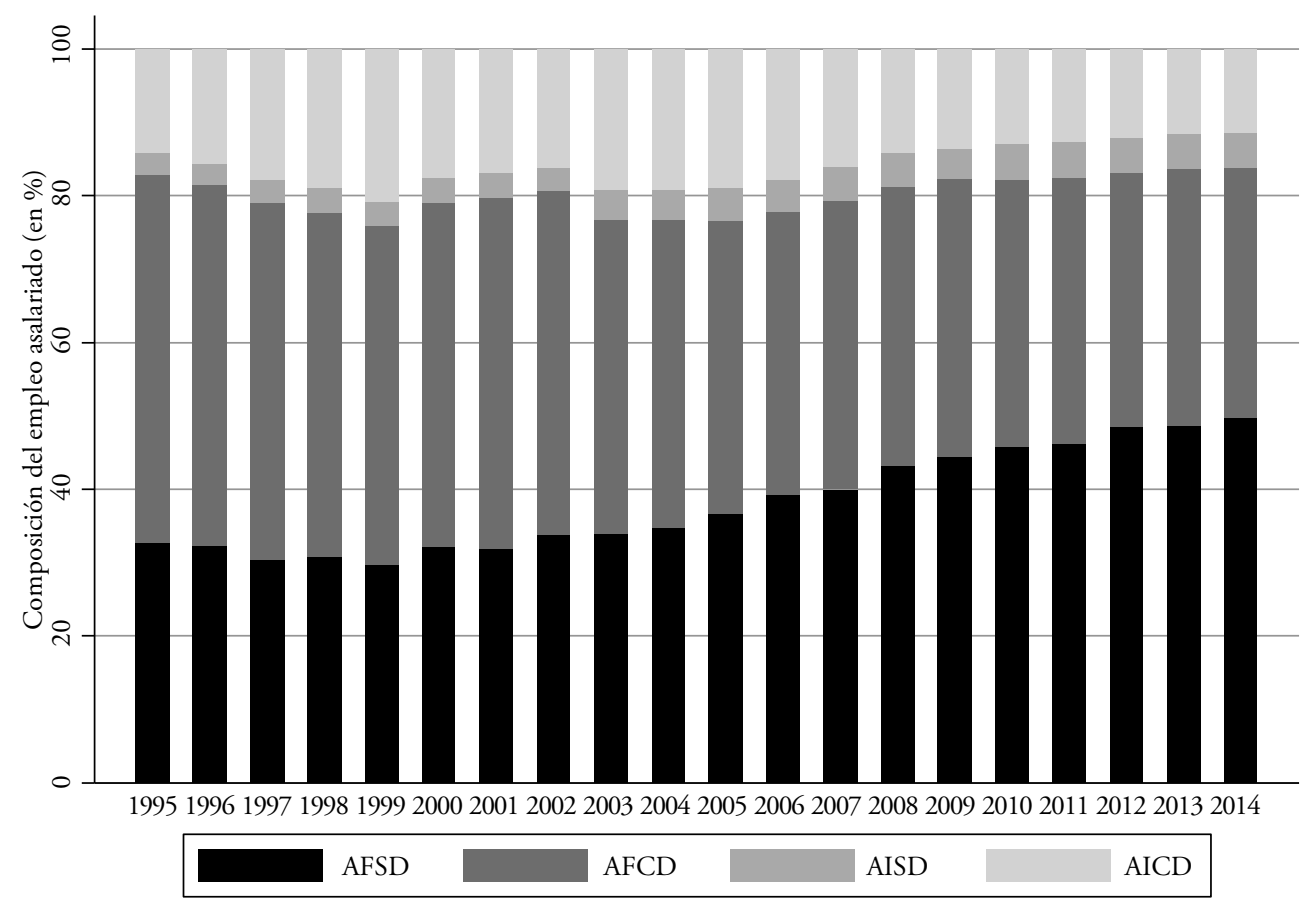

Fuente: Elaborado a partir de los microdatos de la EPH. 
En cuanto a la calificación de la tarea desempeñada se aprecia que una mayor proporción de los puestos asalariados en las MGEySP corresponden a operarios. No obstante, el porcentaje de AFSD ( $31 \%$ en promedio) y de AFCD ( $21 \%$ en promedio) con calificación técnica también es relativamente alto. En cambio, las tareas sin calificación tienen una participación importante entre los AICD (29\% en promedio) y los AISD ( $23 \%$ en promedio). Además, el porcentaje de AFSD profesionales (entre el 12\% y el 16.5\%) supera al del resto de los asalariados, excepto el observado entre los AISD en algunos años $(1998,2001,2004-2008)$.

Por otra parte, la inserción sectorial más común de los asalariados en las MGEySP tiene lugar en la rama de servicios sociales y de administración pública y en menor medida en la de industria y el transporte. No obstante, existen algunas diferencias entre los grupos. Así, en comparación con los AF, los AICD se concentran más en los sectores de la construcción y de comercio, restaurantes y hoteles.

El análisis de los años de antigüedad laboral revela importantes diferencias entre los grupos de asalariados considerados. En efecto, mientras los puestos AFCD y AFSD presentan un alto porcentaje de trabajadores que se desempeñan hace más de 5 años en su ocupación (62\% y 49\%, en promedio, respectivamente), lo contrario ocurre entre los AICD y AISD. Así, se aprecia que los puestos de trabajo de 1 a 5 años de antigüedad son más característicos de los AISD y aquellos con menos de un año de antigüedad son propios de los AICD. No obstante, la participación de los empleos de mayor antigüedad (con más de 5 años) entre los AICD crece 10 puntos porcentuales durante 1995-2014.

Finalmente, se observa que un mayor porcentaje de AFSD y AFCD (más del 41\% y del $23 \%$, respectivamente) se encuentra en el sector público en comparación con los AICD y AISD que están ocupados principalmente en empresas que contratan entre 6 a 25 empleados. En promedio, 67\% de los AICD y el 63\% de los AISD trabaja en dichas empresas. En cambio, los puestos de trabajo de los AFSD participan en mayor proporción en las empresas de 26 a 100 empleados y en menor medida en las empresas de 6 a 25 empleados. Por su parte, la proporción de AFCD ocupados en las empresas de 6 a 25 empleados es similar a la empleada en firmas de 26 a 100 empleados.

En resumen, la mayoría de los asalariados en las MGEySP son varones, de edad central (30 a 49 años), que lograron completar el nivel secundario pero no el universitario y que se encuentran ocupados en la rama de servicios sociales y de la administración pública. No obstante, se aprecian algunas características diferentes entre los grupos analizados. Así, en general, la participación de jóvenes y de trabajadores con nivel educativo bajo es mayor entre los AICD y AISD que entre los AFSD. Además, cuando se clasifica a los asalariados según su antigüedad laboral, se observa que un elevado porcentaje de los AFCD y AFSD tienen más de 5 años en su puesto. En cambio, la mayoría de los AICD y de los AISD tienen una antigüedad que no supera los 5 años. Asimismo, un mayor porcentaje de AFSD y AFCD está empleado en el sector público en comparación con los AICD y AISD que están ocupados principalmente en empresas que contratan entre 6 a 25 empleados. 


\section{EVALUACIÓN DE LAS HIPÓTESIS DE ESTUDIO}

Como se mencionó previamente, una de las pruebas empíricas de que un mercado de trabajo está segmentado consiste en la estimación de diferencias salariales entre los segmentos considerados. La razón de ello radica en que en un mercado de trabajo segmentado, la pertenencia a un determinado segmento o categoría laboral (AFSD, AFCD, AICD o AISD, en este caso) produce retornos salariales distintos a iguales atributos personales de los trabajadores. Para estimar estas brechas salariales se implementa el método de efectos fijos (FE) dadas las ventajas que presenta este método respecto al de MCO. La más importante está asociada con el efecto que pueden tener sobre el ingreso laboral ciertas características inobservadas de los trabajadores que el método de MCO no permite considerar. Además, esta metodología no permite estimar el cambio salarial asociado al tránsito de un puesto laboral a otro realizado por un mismo individuo. Esto último es fundamental para la prueba de segmentación laboral, dado que para poder concluir a favor de esta hipótesis, las diferencias salariales no deben explicarse por las características observables e inobservables del trabajador, sino por su segmento de ocupación. De modo que si las brechas salariales se estiman por MCO, es decir, para diferentes individuos, la prueba de segmentación es más débil que la que surge de comparar a un mismo individuo. Estas desventajas son superadas por el método de FE pues, por un lado, permite abordar los posibles problemas de heterogeneidad inobservada controlando por características observables e inobservables de los trabajadores. Por otra parte, permite considerar los cambios en el ingreso laboral asociados con las transiciones que un mismo individuo realiza desde un segmento hacia otro ${ }^{15}$. De manera que las brechas salariales así estimadas indican el incremento o disminución porcentual en el ingreso laboral de un mismo trabajador como resultado de esa transición. Es decir, para cada uno de los ocupados que se desplazaron desde un segmento laboral a otro, se computa la diferencia porcentual entre el ingreso que obtenía en la categoría inicial con el que percibe en la categoría final. En este sentido, el modelo compara el ingreso laboral de trabajadores con similares atributos observables e inobservables.

El modelo econométrico a estimar es el siguiente:

$$
w_{i t}=\beta X_{i t}+\phi I_{i t}+\alpha_{i}+\varepsilon_{i t}
$$

\footnotetext{
15 No obstante, existen una serie de limitaciones asociadas a la estimación de las brechas salariales mediante efectos fijos. Por un lado, el método de FE no controla por ciertas variables omitidas inobservables que varían en el tiempo ni, principalmente, por ciertos beneficios no pecuniarios asociados al puesto que pueden influir en la decisión voluntaria sobre en qué segmento desempeñarse. A pesar de ello, es posible que esas características inobservables variantes en el tiempo así como los beneficios no pecuniarios no produzcan un sesgo significativo en las brechas salariales estimadas considerando que la características inobservables que varían en el tiempo no son numerosas y que los efectos de las variables inobservables asociadas a los beneficios no pecuniarios que no varían en el tiempo son eliminados mediante el método EF. Otro de los problemas de la implementación de esta estrategia a partir de los datos de la EPH es la reducción del número de observaciones (Bertranou et al., 2014).
} 
Donde $w_{i t}$ es el logaritmo del ingreso laboral del i-ésimo trabajador en el año $t ; X_{i t}$ es el vector de características observables del ocupado (su sexo, experiencia potencial, educación y posición en el hogar) y del puesto de trabajo (horas trabajadas, presencia de un jefe de hogar, antigüedad laboral en el puesto de trabajo, calificación de la tarea y ramas de actividad); $\alpha_{i}$ es el conjunto de características inobservables del trabajador invariantes en el tiempo; $I_{i t}$ es la variable dummy que indica la categoría laboral del trabajador y $\varepsilon_{i t}$ es el término de error que se asume cumple con el supuesto de exogeneidad estricta. El signo y tamaño del parámetro asociado a la dummy $I_{i t}$ indica el sentido y la magnitud del diferencial salarial promedio que produce de manera independiente la inserción en un determinado puesto laboral en comparación con otro, es decir, controlando por el efecto de otros atributos personales y otras características del puesto de trabajo.

Como el ingreso laboral se observa solo para aquellos que están empleados y, según los resultados económicos estándares, es probable que la selección dentro de la fuerza laboral o dentro del empleo esté correlacionada con los ingresos laborales potenciales ${ }^{16}$, se corrigen las estimaciones de las brechas de ingresos debido a este problema de sesgo de selección. Con este objetivo, siguiendo a Wooldridge (1995), se estima la siguiente ecuación de selección, que supone presenta la forma Tobit para datos longitudinales:

$$
h_{i t}=\max \left(0, X_{i} \psi_{t}+v_{i t}\right)
$$

Donde $h_{i t}$ son las horas trabajadas; $\mathrm{v}_{i t} \mid X_{i t} \sim N\left(0, \sigma_{t}^{2}\right), w_{i t}$ es observado si $h_{i t}>0$. Bajo el supuesto de que para algún efecto inobservado $g_{i} E\left(\varepsilon_{i t} \mid X_{i}, \alpha_{i}, g_{i}, v_{i t}\right)=E\left(\varepsilon_{i t} \mid g_{i}, v_{i t}\right)=g_{i}+\rho v_{i t}$ se tiene que:

$$
E\left(w_{i t} \mid X_{i}, \alpha_{i}, g_{i}, v_{i t}\right)=\beta X_{i t}+\phi I_{i t}+\rho v_{i t}+f_{i}
$$

Donde $f_{i}=\alpha_{i}+g_{i}$. Por lo tanto, la estimación de (2.1) por efectos fijos utilizando los datos longitudinales produciría estimaciones consistentes de $\beta, \phi y \rho$. Para esto, se reemplazan los términos de error $\mathrm{v}_{i t}$ por los residuos Tobit $\hat{v}_{i t}$ obtenidos de la estimación de la ecuación $(2.2)^{17}$ para cada ańo t.

Por otra parte, con el objetivo de comprobar si el modelo de efectos fijos es más adecuado que el de efecto aleatorios se computa el test de Hausman (1978) a partir de los datos longitudinales para el período 1995-2014 para determinar si el estimador de efectos fijos es consistente. Los resultados obtenidos de implementar el test de Hausman indican que en todos los casos es posible rechazar la hipótesis nula de igualdad entre el estimador de efectos fijos y el estimador de efectos aleatorios al 99\% de confianza. Esto justifica la elección de los estimadores de efectos fijos.

\footnotetext{
16 Para más detalles, véase Heckman (1979) y Vella (1998).

${ }^{17}$ En el modelo Tobit de las horas trabajadas se incluyeron como variables explicativas la edad, el sexo, la educación, el estado civil, la asistencia a un establecimiento educativo, la presencia de un jefe y cónyuge de hogar ocupados y el número de nińos o nińas menores de 5 años en el hogar.
} 
La segunda prueba de segmentación requiere verificar que las brechas salariales se producen por la existencia de una movilidad laboral limitada que impide a los trabajadores desplazarse al segmento de empleo que les corresponde dadas sus características laborales. Estas barreras se espera que sean particularmente altas cuando el destino del tránsito laboral son los puestos de mayor calidad. La estrategia empírica utilizada para ello consiste en estimar tasas brutas de transición y probabilidades condicionadas de transición a partir de un modelo Logit.

Para estimar las probabilidades brutas de transición se computan matrices de transición. A partir de ellas es posible tabular la probabilidad condicional $\left(P_{i j}\right)$ de encontrar a un trabajador en la categoría ocupacional $\mathrm{j}$ al final del período considerado, dado que el trabajador estuvo en la categoría i al comienzo. Cada fila de la matriz de transición suma uno y los elementos de la diagonal principal reflejan la probabilidad de permanecer al final del período en la misma categoría ocupacional de la que se proviene.

Por otra parte, a fin de analizar si los patrones de movilidad laboral entre los segmentos varían con las características de los trabajadores, se estima el siguiente modelo Logit para estimar la probabilidad de que un asalariado que se encuentra ocupado inicialmente en un puesto de trabajo con déficit de calidad de empleo (ya sea porque es un AISD, un AICD o un AFCD), transite hacia un puesto de mayor calidad a lo largo de un año. Se considera que un puesto de mayor calidad para los AI es un puesto formal con o sin déficit de calidad. Lógicamente un puesto de mayor calidad para los AFCD es un puesto formal sin ningún déficit de calidad (AFSD).

$$
P\left(Y_{i}=1 \mid X_{i}\right)=\frac{\exp \left(X_{i} \beta\right)}{1+\exp \left(X_{i} \beta\right)}
$$

$\mathrm{El}$ vector de variables $\mathrm{X}$ en el modelo Logit incluyen variables de género, dummies por grupos de edad, dummies por nivel educativo, estado civil, la asistencia a un establecimiento educativo, la presencia de un jefe de hogar, dummies por rama de actividad, por calificación de la tarea, por tamaño de la firma y por antigüedad en la ocupación.

Asimismo mediante el modelo Logit se busca estimar las probabilidades predichas de cada transición laboral considerada así como analizar las características observables de los individuos que aumentan o disminuyen la probabilidad de ocupar un determinado puesto de trabajo.

\section{RESULTADOS DEL ANÁLISIS DE LAS HIPÓTESIS DE SEGMENTACIÓN LABORAL}

En esta sección se presentan los resultados de la estimación de las brechas salariales y los patrones de movilidad laboral entre las categorías laborales consideradas a fin de probar cada una de las hipótesis de segmentación laboral que se formularon en la sección 3 con relación a la estructura del mercado de trabajo en las MGEySP. Dado que el período 1995-2014 es muy extenso para realizar un análisis para cada año, se seleccionan algunos 
años característicos de cada década. Así el período 1996-1997 corresponde al ciclo de recuperación económica registrado durante la década de 1990 mientras que los años 2001-2002 son de crisis económica. En cambio, el período 2006-2007 caracteriza la senda de crecimiento económico observada luego de la crisis de 2001-2002, en tanto que durante 2012-2013 tuvo lugar una ralentización económica. Asimismo, estos períodos permiten analizar los resultados con una frecuencia de 5 años.

\subsection{Brechas SAlariales ENTRE LaS Distintas CATEgorías laborales}

A continuación se presentan los resultados obtenidos de las brechas salariales estimadas entre las categorías laborales previamente definidas: AFSD, AFCD AICD y AISD para probar las diferentes hipótesis de segmentación laboral formuladas.

En el Gráfico 2 se presentan los resultados de las brechas salariales ${ }^{18}$ estimadas entre las categorías laborales previamente definidas para probar las diferentes hipótesis de segmentación laboral formuladas ${ }^{19}$. El eje horizontal muestra los períodos bajo análisis mientras que el eje vertical mide la magnitud y signo de la brecha salarial estimada. Los puntos sobre la línea sólida en azul corresponden a la brecha salarial estimada entre las categorías laborales analizadas. Estos puntos deben interpretarse como el cambio promedio en el ingreso laboral mensual real que produce de manera independiente la transición que realiza un mismo individuo desde un puesto de trabajo de mala calidad hacia otro de buena calidad, es decir, controlando por el efecto de sus atributos personales y laborales. Las líneas de color rojo punteadas en el Gráfico 2 corresponden a los intervalos de confianza. De modo que si la línea azul gruesa se encuentra entre dichas líneas y alejada del cero, las brechas estimadas son estadísticamente significativas.

${ }_{18}$ Para estimar las brechas salariales se considera el ingreso mensual de la ocupación principal. Dado que algunas actividades en el mercado laboral tienen restringidas las horas de trabajo, se considera que los ingresos laborales mensuales reflejan mejor las oportunidades de ingresos que los salarios horarios. Por otra parte, en Argentina, los ingresos laborales generalmente se negocian en términos mensuales. Además, la información recogida por la EPH dificulta el cómputo correcto del ingreso horario. El problema se deriva de la inconsistencia temporal de la información necesaria para tales fines. Por un lado, los datos de los ingresos laborales provienen del mes anterior a la entrevista. Por otra parte, se presenta información sobre las horas trabajadas durante la semana de referencia, posterior a la percepción de los ingresos. Además, como la EPH no indaga al ocupado sobre el monto de su ingreso laboral bruto o neto se asume, en general, que el ingreso reportado por los trabajadores es el neto y no el bruto dado que es más probable que el asalariado recuerde y declare su ingreso neto de impuestos laborales. Asimismo, es importante señalar que como las brechas salariales fueron estimadas controlando por horas trabajadas no se incurre en sesgos debido a diferencias en productividad causadas por una jornada laboral horaria distinta entre los asalariados. Pese a ello, se estimaron dichas brechas salariales considerando el ingreso laboral horario. Este ejercicio no modificó las principales conclusiones de este estudio. 19 Dado que el período 1995-2014 es muy extenso para realizar un análisis para cada ańo, se seleccionan algunos años característicos de cada década. Así el período 1996-1997 corresponde al ciclo de recuperación económica registrado durante los noventa mientras que los años 2001-2002 son de crisis económica. En cambio, el período 2006-2007 caracteriza la senda de crecimiento económico observada luego de la crisis de 2001-2002, en tanto que durante 2012-2013 tuvo lugar un enlentecimiento económico. Asimismo, estos períodos permiten analizar los resultados con una frecuencia de 5 ańos. 
Gráfico 1. Brechas salariales condicionadas asociadas con las transiciones entre categorías laborales estimadas con el método de FE

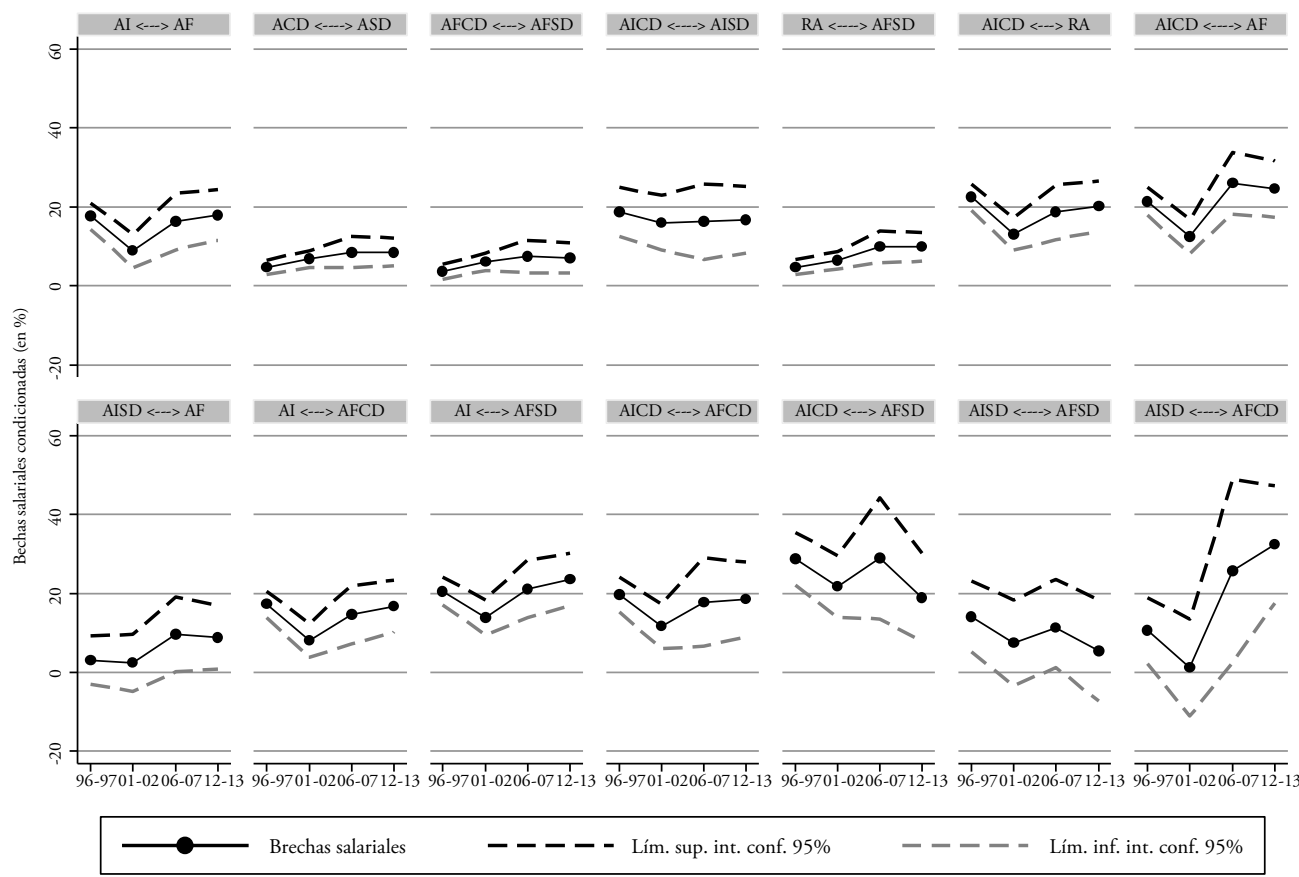

Fuente: Elaborado a partir de los microdatos de la EPH.

Nota: $\leftrightarrow$ denota transiciones o trayectorias entre categorías laborales. RA: resto de los asalariados no considerados en la categoría de comparación.

La evidencia obtenida confirma algunas de las hipótesis de segmentación laboral formuladas. Entre ellas, la presencia de un segmento compuesto por empleados formales y otro por empleados informales. En el Gráfico 2 se aprecia una brecha positiva y significativa asociada con las transiciones desde empleos informales hacia puestos formales cuando se controla por el déficit en otros atributos relacionados con la calidad del empleo (primer Gráfico de la primera fila). No obstante, la variable dummy que controla por la existencia de déficits en otros atributos relacionados con la calidad del empleo también resultó estadísticamente significativa en todos los períodos considerados, aun controlando por la presencia de informalidad laboral. Esta evidencia revela dos puntos importantes en relación con la hipótesis central de estudio. Por un lado, si el análisis si hubiera realizado puramente desde el enfoque de la informalidad laboral, como lo hacen la mayoría de los estudios existentes en la Argentina, se ignoraría el hecho que este no es el único fenómeno susceptible de producir segmentación laboral en las MGEySP. Por otra parte, si se consideran otros atributos de la calidad del empleo en forma conjunta, la evidencia sugiere que la segmentación laboral puede producirse tanto entre como dentro del empleo asalariado formal e informal. Por ello, se estimaron brechas 
de ingresos entre AICD y AISD así como entre AFCD y AFSD obteniendo evidencia a favor de ambas hipótesis de segmentación (tercer y cuarto Gráfico de la primera fila). No obstante, la magnitud de estas brechas es significativamente más grande entre los primeros en comparación con los segundos. Esto sugiere que las penalidades salariales asociadas con los déficits en otros atributos de la calidad del empleo son mayores cuando el puesto de trabajo no está registrado que cuando lo está. De allí que, las brechas salariales más altas corresponden a las transiciones desde los peores hacia los mejores puestos, es decir, desde los empleos AICD hacia los empleos AFSD (quinto Gráfico de la segunda fila). Además, los diferenciales salariales estadísticamente significativos que se observan entre los AFSD y el RA así como entre los AICD y el RA, confirman que los segmentos formados por los peores o los mejores empleos existen, cualquiera sea el grupo de comparación (quinto y sexto Gráfico de la primera fila). En consecuencia, se espera por un lado, que el acceso a los empleos AFSD se encuentre restringido para cualquier categoría laboral de asalariados dentro de las MGEySP y por otro, que los AICD tengan dificultades para moverse hacia empleos de mejor calidad, ya sean empleos formales o empleo informales sin déficit.

Asimismo, se observa que la segmentación laboral en las MGEySP se produce en mayor magnitud entre algunos segmentos. Por ejemplo, cuando se consideran las transiciones entre los AFCD (o AFSD) y el conjunto de AI, las brechas salariales estimadas son estadísticamente significativas y más elevadas que las correspondientes entre los AFCD y los AFSD. En principio, esta evidencia puede sugerir que la segmentación se produce más por la condición de informalidad laboral de los empleados que por los otros déficits de calidad del empleo. Sin embargo, las brechas de ingreso entre los AICD y AISD son de una magnitud similar a las que existen entre AICD y AFCD. Además, los resultados no confirman la presencia de segmentación entre los AISD y AFSD (sexto Gráfico de la segunda fila). Esto último sugiere que la segmentación laboral no surge por la mera existencia de empleos formales e informales, sino que esta se profundiza por la presencia de déficit en otros atributos de la calidad. No obstante, la falta de significatividad estadística de la brecha entre AISD y AFSD puede deberse a las bajas transiciones entre puestos. Este supuesto es corroborado a partir de los patrones de movilidad laboral que se presentan en la siguiente subsección.

Por otra parte, la evolución de las diferencias salariales sugiere que, en relación con el período 1996-1997, las brechas caen durante 2001-2002, crecen en 2006-2007 pero, luego permanecen relativamente estables (Cuadro A7). La crisis de 2001-2002 produjo la caída de los salarios de los empleados siendo de mayor magnitud entre los trabajadores ocupados en los peores puestos que entre aquellos en empleos de más calidad. No obstante, durante este período, se observa una caída de las brechas salariales estimadas principalmente entre AI y AF con o sin déficits en otros atributos de la calidad del empleo. Si bien este cambio puede resultar contra-intuitivo, los resultados obtenidos por FE dependen de las transiciones laborales. Justamente, la caída de los diferenciales 
salariales durante 2001-2002 parece estar asociada con una reducción significativa de la movilidad laboral desde empleos AI hacia empleos AF.

Las razones detrás de los incrementos observados en las brechas salariales en 20062007, están asociadas con el aumento de los salarios reales de todos los trabajadores, siendo mayor entre los AFSD. Este último incremento puede responder a múltiples factores como los aumentos del salario mínimo, el crecimiento económico, la revitalización del papel de los sindicatos, el incremento de la proporción de empleos de mejor calidad en las MGEySP, entre otros. El crecimiento de las brechas salariales en un contexto de crecimiento económico y de un esquema institucional favorable para la reducción de los empleos de mala calidad, sugiere que si no se modifican los incentivos del lado de la demanda, la segmentación laboral puede persistir e incluso profundizarse entre los grupos. Así, por ejemplo, las políticas de formalización laboral llevadas a cabo durante los dos mil, lograron una reducción del empleo informal pero, simultáneamente pudieron haber motivado a las MGEySP a buscar otros mecanismos de reducción de costes laborales, como el incumplimiento del salario mínimo entre los AI, que se traducen en un empeoramiento de las condiciones de empleo y esto a su vez, en una profundización de la segmentación laboral en las MGEySP. Asimismo, la marcada estabilidad que se aprecia en las brechas salariales en el período de ralentización económica podría responder, en parte, a que la composición de los grupos según sexo, nivel educativo, edad y calificación de la tarea no se modificó sustancialmente entre 2006-2007 y 2012-2013.

A fin de identificar los principales factores que podrían explicarla. Para esto se utiliza la descomposición propuesta por Juhn et al. (1993) que permite determinar qué proporción de las variaciones observadas en las brechas salariales responde a los cambios en las características de los trabajadores y del puesto, a los cambios en los retornos de esas características y a las modificaciones en el grado de segmentación laboral entre los períodos analizados. Así, pues, el método de Juhn et al. (1993) descompone los cambios en las diferencias salariales estimadas entre los segmentos analizados a lo largo del tiempo en cuatro componentes: i) el efecto cantidad que corresponde al cambio observado en los atributos de cada trabajador y del puesto, ii) el efecto precio que captura las variaciones en los retornos o en los coeficientes de dichas características, iii) el efecto interacción que está relacionado con la combinación de los dos efectos previos y iv) el efecto no explicado debido a los cambios en factores inobservables.

En el Cuadro A8 se presenta la descomposición en los cuatro efectos previamente mencionados del cambio observado en la brecha salarial entre 1996-1997 y 2001-2002, entre 2001-2002 y 2006-2007 así como entre 2006-2007 y 2012-2013. Los signos negativos en el cambio de la brecha salarial indican que en la mayoría de los casos el diferencial de ingreso entre los segmentos analizados disminuye entre 1996-1997 y 2001-2002. En cambio, entre 2006-2007 y 2012-2013 se observa mayoritariamente un aumento en la magnitud de las brechas. Asimismo, los resultados revelan que la mayor parte de los cambios temporales en las brechas salariales estimadas responden principalmente 
al componente no explicado o a factores inobservados que pueden estar asociados con la segmentación laboral. De este modo, la disminución o el incremento de los diferenciales de ingreso entre los períodos parece estar, en gran medida, relacionado con el cambio en las tasas de movilidad laboral, esto es, con el porcentaje de trabajadores que cambian de segmento de ocupación de un período a otro. Así, por ejemplo, la reducción de la brecha salarial entre 1996-1997 y 2001-2002 puede atribuirse a una mayor entrada de los trabajadores a puestos con déficit de calidad del empleo que incrementa la participación de este tipo de puestos en las MGEySP durante la crisis macroeconómica de 2001-2002. Esto último, a su vez, podría haber reducido la heterogeneidad en la calidad de los puestos de trabajo en las MGEySP de un período a otro, pues una mayor cantidad de trabajadores se encuentran ocupados en empleos de mala calidad. En consecuencia, se observa una menor brecha salarial entre los segmentos analizados. Por el contrario, el aumento de varias brechas salariales que se aprecia entre 2001-2002 y 2006-2007 puede estar asociado con el incremento de los puestos de trabajo sin ningún déficit en dichos períodos. Como resultado de esto, el mercado de trabajo de las MGEySP puede haberse polarizado aún más entre empleos de mala y buena calidad. Por lo tanto, dado que una mayor proporción de trabajadores se desempeña en empleos de buena calidad y percibe un salario más alto que los trabajadores en puestos de mala calidad se observa una mayor brecha salarial entre los segmentos analizados. En consecuencia, la segmentación laboral persiste durante esos años a pesar del crecimiento de los empleos de calidad.

En cambio la evolución de los diferenciales salariales estimados entre los AISD y los AF, tanto con déficit de calidad del empleo como sin déficit de calidad, se explica en mayor medida por la porción explicada. El cambio más significativo tiene lugar entre 2001-2002 y 2006-2007 cuando la brecha de ingresos cae principalmente como resultado de un efecto cantidad y un efecto precio negativos. Por tanto, en este caso, la reducción de la brecha salarial se atribuye en parte a una menor heterogeneidad en las características individuales y laborales de los trabajadores AISD con respecto a los AF con déficit y sin déficit de calidad. También el efecto precio negativo indica que los retornos de dichas características, entre los AISD en relación con los grupos de comparación, experimentaron un incremento entre los períodos analizados. Esta evidencia es consistente con las mayores tasas de entrada a empleos de mayor calidad que se observan entre estos empleados durante 2006-2007 y por tanto, con una menor segmentación laboral.

Los resultados de la descomposición de Juhn et al. (1993) confirman las conclusiones obtenidas previamente. Así, pues, esta evidencia indica que, en la mayoría de los casos, los cambios en las características de los trabajadores no son responsables de la evolución observada en las brechas salariales estimadas entre los segmentos, que parece estar más asociada con modificaciones en factores no observables. Entre ellos se pueden incluir las barreras a la entrada que experimentan los trabajadores que se desplazan desde los empleos con déficits hacia puestos de trabajo de mayor calidad. 
En conclusión, conforme con los resultados obtenidos hasta aquí, es posible afirmar que la informalidad laboral no es la única causa de segmentación del mercado de trabajo en las MGEySP. Los déficits en otros atributos de la calidad del empleo también tienen un efecto sobre la estructura del mercado de trabajo de las MGEySP, aunque de manera distinta dentro de los AI y los AF. Por lo tanto la segmentación laboral parece producirse tanto entre como dentro de los empleos formales y los empleos informales. Particularmente, la evidencia obtenida a partir de la estimación de las diferencias salariales, entre las cuatro categorías laborales, señala la presencia de al menos cuatro segmentos laborales en las MGEySP, dos formados por los AF y otros dos formados por los AI. No obstante, las brechas salariales resultaron más altas entre los AICD y los AISD que entre los AFCD y los AFSD. Esto sugiere que la segmentación del mercado de trabajo es mayor dentro los AI que dentro los AF.

Si bien esta evidencia contradice la denominada teoría de voluntariedad del empleo informal, no se descarta que una proporción de los asalariados no registrados, principalmente aquellos sin déficits en otros atributos de la calidad del empleo (AISD), decidan estar ocupados en esos puestos a partir de un análisis de los costes y beneficios del registro en el sistema de seguridad social, principalmente cuando pueden sustituir la pérdida de esos beneficios mediante otros mecanismos como los programas universales o los familiares. Una forma de explorar esta hipótesis es analizando si la probabilidad de estar empleado en un puesto informal es mayor para quienes tienen un miembro del hogar ocupado en puesto formal. A fin de examinar esto, se estimó un modelo Logit ${ }^{20}$. Los resultados obtenidos que no corroboran la hipótesis mencionada. La presencia de un jefe de hogar que se encuentra ocupado como asalariado formal no aumenta, entre los otros miembros del hogar, las probabilidades de trabajar en un empleo informal. Aun cuando la provisión de los beneficios asociados a la protección social sea ineficiente y costosa, es poco probable que estos trabajadores busquen voluntariamente los puestos informales, considerando todos los otros déficits generalmente asociados con la informalidad laboral (como la inestabilidad o insatisfacción laboral). En este sentido, es válido preguntarse ¿qué características no pecuniarias son tan valiosas como para que, a pesar de todos los aspectos negativos de un empleo informal o de baja calidad, el trabajador continúe eligiendo esta opción como la más ventajosa?

\footnotetext{
20 La variable dependiente mide la probabilidad de que un individuo se encuentre ocupado como trabajador informal en las MGEySP. Las variables explicativas más relevantes, en este caso, son la presencia de un jefe de hogar ocupado como trabajador formal, la presencia de un cónyuge en el hogar, una variable de interacción entre ambas variables. El resto de las variables independientes incluyen dummies de regiones de residencia, la cantidad de menores de cinco años en el hogar, el sexo, dummies por grupos de edad, dummies por nivel educativo, estado civil, la asistencia a un establecimiento educativo, dummies por rama de actividad, por calificación de la tarea, por tamaño de la firma y por antigüedad en la ocupación.
} 


\subsection{Patrones de movilidad laboral}

A continuación se estudian los patrones de movilidad laboral entre los segmentos encontrados en las MGEySP, AFSD, AFCD, AISD y AICD. El objetivo de este análisis es comprobar si existe una limitada movilidad laboral entre y dentro de los cuatro segmentos señalados previamente. En particular se espera encontrar bajas tasas de transición desde empleos de baja calidad (AFCD, AISD y AICD) hacia los de mejor calidad (AFSD). Las matrices de transición computadas en el Cuadro 1 dan cuenta de una mayor estabilidad entre los empleos formales sin ningún déficit de calidad (AFSD) en relación con el resto de los empleos de las MGEySP. Además, mientras que en la segunda mitad de la década de 1990 , cerca de un $58 \%$ de estos trabajadores permanecían al menos un año en ese puesto, ese porcentaje se elevó al 74,2\% en 2012-2013. En cambio, la tasa de permanencia, entre los asalariados informales (AI), no supera el $27 \%$. Esto sugiere una mayor estabilidad de los empleos AFSD y AFCD en comparación con los AISD y AICD.

Por otra parte, los nuevos trabajadores AFSD provienen con mayor intensidad de otros puestos y en menor medida de la inactividad y el desempleo. En todos los períodos analizados, este grupo de trabajadores proceden, en mayor proporción de un empleo AFCD que de un puesto asalariado informal. Asimismo, cerca del 22\% de los AFSD en los noventa y entre un $12 \%$ y un $24 \%$, en los dos mil transitan hacia un puesto AFCD. Estas transiciones son de mayor intensidad durante las crisis que en períodos de recuperación.

En el caso de los AFCD puede observarse que la tasa de permanencia en sus puestos se redujo 7,4 puntos porcentuales con la crisis de 2001-2002 pero en el resto del período permaneció relativamente estable. Una vez pasada la crisis económica, el porcentaje de AFCD que logran insertarse, al cabo de un año, en empleos sin ningún déficit se incrementó 9 puntos porcentuales. Esto sugiere que el crecimiento económico favorece la creación de puestos AFSD en las MGEySP. Sin embargo, un porcentaje considerable de AFCD que salen de esa ocupación, entre el 35\% y el 53\%, terminan en un empleo de baja calidad (AISD o AICD) o fuera del mercado laboral al cabo de un año.

Entre los AICD se aprecia que de un $19 \%$ a un $27 \%$ permanecen en sus puestos, siendo esta tasa de permanencia menor en períodos de crisis y mayor en períodos de recuperación. De modo que la gran mayoría de estos trabajadores — más del 73\%dejan esos puestos. Pero, la mayor movilidad de los AICD no está asociada con una mayor probabilidad de ingresar a empleos AFSD. Por el contrario, al cabo de un ańo, una importante proporción de estos asalariados, entre el $53 \%$ y el $71 \%$, se dirige fuera de las MGEySP, ya sea hacia puestos en pequeñas empresas (PE), hacia trabajos por cuenta propia o bien hacia la inactividad o la desocupación.

Los patrones laborales entre los AISD son similares a los de los AICD, aunque de menor intensidad. No obstante, también existe un flujo de movilidad atendible desde 
los empleos AISD hacia empleos AFSD (entre el 13\% y el 17\%). Sin embargo, si se considera que del $75 \%$ al $91 \%$ de los AISD dejan su puesto, la tasa de entrada a empleos AFSD es baja con relación a los otros desplazamientos que realizan los AISD. Esta evidencia sugiere que la falta de significancia estadística de las brechas salariales asociadas con las transiciones entre AFSD y AISD, que se computan con el método FE podría responder, en parte, a la baja intensidad de esas transiciones que no superan el $16,4 \%$. Por lo tanto, no es posible descartar totalmente la existencia de una segmentación laboral entre estos dos tipos de empleo en las MGEySP.

Cuadro 1. Matrices de transición laboral, 1995-2014

\begin{tabular}{|c|c|c|c|c|c|c|c|c|c|c|c|c|c|c|}
\hline \multirow{5}{*}{$\begin{array}{l}\text { Estado en el período } \\
\text { inicial/Estado en el período final }\end{array}$} & \multirow{3}{*}{\multicolumn{2}{|c|}{$\begin{array}{c}\text { Inactivos o } \\
\text { desocupados }\end{array}$}} & \multicolumn{8}{|c|}{ Asalariados en las MGEySP } & \multirow{3}{*}{\multicolumn{2}{|c|}{$\begin{array}{c}\text { Asalariados de } \\
\text { PE }\end{array}$}} & \multirow{3}{*}{\multicolumn{2}{|c|}{$\begin{array}{c}\text { Trabajadores } \\
\text { independientes }\end{array}$}} \\
\hline & & & \multicolumn{4}{|c|}{ Asalariados formales } & \multicolumn{4}{|c|}{ Asalariados informales } & & & & \\
\hline & & & \multicolumn{2}{|c|}{ Sin déficit } & \multicolumn{2}{|c|}{ Con déficit } & \multicolumn{2}{|c|}{ Sin déficit } & \multicolumn{2}{|c|}{ Con déficit } & & & & \\
\hline & \multicolumn{14}{|c|}{ Probabilidad de desplazarse desde una categoría inicial a una terminal } \\
\hline & \multicolumn{14}{|c|}{$1996-1997$} \\
\hline Inactivos o desocupados & $80.9 \%$ & $(0.006)$ & $1.2 \%$ & $(0.002)$ & $1.4 \%$ & $(0.002)$ & $0.4 \%$ & $(0.001)$ & $2.9 \%$ & $(0.003)$ & $8.0 \%$ & $(0.004)$ & $5.2 \%$ & $(0.004)$ \\
\hline \multicolumn{15}{|l|}{ Asalariados de MGEySP } \\
\hline \multicolumn{15}{|l|}{ Asalariados formales } \\
\hline Sin déficit & $9.1 \%$ & $(0.013)$ & $57.9 \%$ & $(0.021)$ & $21.7 \%$ & $(0.018)$ & $0.9 \%$ & $(0.004)$ & $1.9 \%$ & $(0.007)$ & $4.9 \%$ & $(0.009)$ & $3.6 \%$ & $(0.008)$ \\
\hline Con déficit & $6.9 \%$ & $(0.011)$ & $22.3 \%$ & $(0.018)$ & $55.0 \%$ & $(0.021)$ & $0.3 \%$ & $(0.001)$ & $3.9 \%$ & $(0.009)$ & $8.2 \%$ & $(0.012)$ & $3.3 \%$ & $(0.007)$ \\
\hline \multicolumn{15}{|l|}{ Asalariados informales } \\
\hline Sin otro déficit & $11.3 \%$ & $(0.041)$ & $16.5 \%$ & $(0.041)$ & $12.8 \%$ & $(0.044)$ & $15.7 \%$ & $(0.054)$ & $10.9 \%$ & $(0.047)$ & $20.9 \%$ & $(0.056)$ & $11.9 \%$ & $(0.044)$ \\
\hline Con déficit & $24.1 \%$ & $(0.030)$ & $2.7 \%$ & $(0.009)$ & $12.4 \%$ & $(0.022)$ & $3.4 \%$ & $(0.014)$ & $26.3 \%$ & $(0.033)$ & $19.8 \%$ & $(0.029)$ & $11.3 \%$ & $(0.022)$ \\
\hline Asalariados de PE & $22.5 \%$ & $(0.013)$ & $2.9 \%$ & $(0.006)$ & $5.4 \%$ & $(0.007)$ & $1.3 \%$ & $(0.004)$ & $4.9 \%$ & $(0.007)$ & $55.2 \%$ & $(0.016)$ & $7.8 \%$ & $(0.008)$ \\
\hline Trabajadores independientes & $16.9 \%$ & $(0.011)$ & $1.3 \%$ & $(0.003)$ & $1.8 \%$ & $(0.004)$ & $1.0 \%$ & $(0.003)$ & $3.7 \%$ & $(0.006)$ & $9.3 \%$ & $(0.009)$ & $66.0 \%$ & $(0.015)$ \\
\hline Total & $48.6 \%$ & $(0.006)$ & $8.6 \%$ & $(0.003)$ & $9.2 \%$ & $(0.003)$ & $0.9 \%$ & $(0.001)$ & $4.1 \%$ & $(0.002)$ & $14.5 \%$ & $(0.004)$ & $14.1 \%$ & $(0.004)$ \\
\hline & & & & & & & 2001 & 2002 & & & & & & \\
\hline Inactivos o desocupados & $85.0 \%$ & $(0.006)$ & $0.5 \%$ & $(0.001)$ & $0.9 \%$ & $(0.002)$ & $0.2 \%$ & $(0.001)$ & $1.3 \%$ & $(0.002)$ & $6.2 \%$ & $(0.004)$ & $5.8 \%$ & $(0.004)$ \\
\hline Asalariados de MGEySP & & & & & & & & & & & & & & \\
\hline Asalariados formales & & & & & & & & & & & & & & \\
\hline Sin déficit & $11.3 \%$ & $(0.015)$ & $56.8 \%$ & $(0.021)$ & $23.6 \%$ & $(0.018)$ & $0.9 \%$ & $(0.004)$ & $2.1 \%$ & $(0.006)$ & $3.5 \%$ & $(0.008)$ & $1.9 \%$ & $(0.005)$ \\
\hline Con déficit & $11.4 \%$ & $(0.013)$ & $24.5 \%$ & $(0.017)$ & $47.8 \%$ & $(0.020)$ & $0.7 \%$ & $(0.003)$ & $3.7 \%$ & $(0.008)$ & $7.9 \%$ & $(0.011)$ & $3.9 \%$ & $(0.008)$ \\
\hline Asalariados inform & & & & & & & & & & & & & & \\
\hline Sin otro déficit & $25.8 \%$ & $(0.065)$ & $14.1 \%$ & $(0.052)$ & $7.8 \%$ & $(0.034)$ & $9.1 \%$ & $(0.041)$ & $9.4 \%$ & $(0.041)$ & $20.8 \%$ & $(0.060)$ & $13.2 \%$ & $(0.051)$ \\
\hline Con déficit & $31.8 \%$ & $(0.033)$ & $1.1 \%$ & $(0.004)$ & $5.8 \%$ & $(0.015)$ & $3.6 \%$ & $(0.015)$ & $18.7 \%$ & $(0.029)$ & $18.7 \%$ & $(0.028)$ & $20.2 \%$ & $(0.031)$ \\
\hline Asalariados de PE & $31.2 \%$ & $(0.015)$ & $2.1 \%$ & $(0.005)$ & $2.6 \%$ & $(0.005)$ & $0.8 \%$ & $(0.003)$ & $3.6 \%$ & $(0.006)$ & $48.0 \%$ & $(0.016)$ & $11.6 \%$ & $(0.011)$ \\
\hline Trabajadores independientes & $25.0 \%$ & $(0.013)$ & $0.6 \%$ & $(0.001)$ & $2.0 \%$ & $(0.005)$ & $0.8 \%$ & $(0.003)$ & $2.6 \%$ & $(0.005)$ & $8.3 \%$ & $(0.009)$ & $60.8 \%$ & $(0.015)$ \\
\hline Total & $52.9 \%$ & $(0.006)$ & $8.5 \%$ & $(0.003)$ & $8.5 \%$ & $(0.003)$ & $0.7 \%$ & $(0.001)$ & $2.8 \%$ & $(0.002)$ & $12.3 \%$ & $(0.004)$ & $14.3 \%$ & $(0.004)$ \\
\hline & & & & & & & 2006 & -2007 & & & & & & \\
\hline Inactivos o desocupados & $80.2 \%$ & $(0.000)$ & $1.4 \%$ & $(0.000)$ & $0.8 \%$ & $(0.000)$ & $0.6 \%$ & $(0.000)$ & $2.3 \%$ & $(0.000)$ & $9.7 \%$ & $(0.000)$ & $5.1 \%$ & $(0.000)$ \\
\hline Asalariados de MGEySP & & & & & & & & & & & & & & \\
\hline Asalariados formales & & & & & & & & & & & & & & \\
\hline Sin déficit & $4.7 \%$ & $(0.000)$ & $72.4 \%$ & $(0.001)$ & $12.2 \%$ & $(0.000)$ & $1.5 \%$ & $(0.000)$ & $0.5 \%$ & $(0.000)$ & $5.0 \%$ & $(0.000)$ & $3.5 \%$ & $(0.000)$ \\
\hline Con déficit & $5.1 \%$ & $(0.000)$ & $33.6 \%$ & $(0.001)$ & $46.9 \%$ & $(0.001)$ & $1.0 \%$ & $(0.000)$ & $3.1 \%$ & $(0.000)$ & $5.4 \%$ & $(0.000)$ & $4.9 \%$ & $(0.000)$ \\
\hline Asalariados informo & & & & & & & & & & & & & & \\
\hline Sin otro déficit & $21.5 \%$ & $(0.002)$ & $16.6 \%$ & $(0.002)$ & $7.8 \%$ & $(0.001)$ & $17.4 \%$ & $(0.002)$ & $9.1 \%$ & $(0.001)$ & $13.3 \%$ & $(0.002)$ & $14.3 \%$ & $(0.002)$ \\
\hline Con déficit & $21.4 \%$ & $(0.001)$ & $4.2 \%$ & $(0.001)$ & $11.3 \%$ & $(0.001)$ & $3.0 \%$ & $(0.000)$ & $27.2 \%$ & $(0.001)$ & $26.4 \%$ & $(0.001)$ & $6.4 \%$ & $(0.001)$ \\
\hline Asalariados de PE & $22.1 \%$ & $(0.000)$ & $5.0 \%$ & $(0.000)$ & $2.5 \%$ & $(0.000)$ & $0.7 \%$ & $(0.000)$ & $4.2 \%$ & $(0.000)$ & $56.5 \%$ & $(0.001)$ & $9.0 \%$ & $(0.000)$ \\
\hline Trabajadores independientes & $14.4 \%$ & $(0.000)$ & $0.9 \%$ & $(0.000)$ & $2.1 \%$ & $(0.000)$ & $1.3 \%$ & $(0.000)$ & $2.3 \%$ & $(0.000)$ & $8.7 \%$ & $(0.000)$ & $70.1 \%$ & $(0.001)$ \\
\hline Total & $43.1 \%$ & $(0.007)$ & $13.0 \%$ & $(0.005)$ & $6.5 \%$ & $(0.004)$ & $1.3 \%$ & $(0.002)$ & $3.7 \%$ & $(0.003)$ & $16.4 \%$ & $(0.006)$ & $16.1 \%$ & $(0.005)$ \\
\hline & & & & & & & 2012 & -2013 & & & & & & \\
\hline Inactivos o desocupados & $81.7 \%$ & $(0.009)$ & $1.8 \%$ & $(0.003)$ & $0.8 \%$ & $(0.002)$ & $0.7 \%$ & $(0.002)$ & $1.7 \%$ & $(0.004)$ & $7.4 \%$ & $(0.006)$ & $5.8 \%$ & $(0.005)$ \\
\hline Asalariados de MGEySP & & & & & & & & & & & & & & \\
\hline Asale & & & & & & & & & & & & & & \\
\hline Sin déficit & $6.0 \%$ & $(0.010)$ & $74.2 \%$ & $(0.018)$ & $11.8 \%$ & $(0.013)$ & $1.4 \%$ & $(0.004)$ & $0.7 \%$ & $(0.003)$ & $4.0 \%$ & $(0.008)$ & $1.9 \%$ & $(0.005)$ \\
\hline Con déficit & $4.9 \%$ & $(0.015)$ & $34.1 \%$ & $(0.034)$ & $48.2 \%$ & $(0.037)$ & $0.0 \%$ & $(0.000)$ & $2.1 \%$ & $(0.011)$ & $6.6 \%$ & $(0.018)$ & $4.0 \%$ & $(0.015)$ \\
\hline Asalariados informales & & & & & & & & & & & & & & \\
\hline Sin otro déficit & $10.9 \%$ & $(0.032)$ & $13.4 \%$ & $(0.043)$ & $8.4 \%$ & $(0.045)$ & $24.7 \%$ & $(0.054)$ & $6.8 \%$ & $(0.036)$ & $16.9 \%$ & $(0.063)$ & $18.9 \%$ & $(0.046)$ \\
\hline Con déficit & $12.6 \%$ & $(0.035)$ & $7.2 \%$ & $(0.021)$ & $9.2 \%$ & $(0.032)$ & $8.6 \%$ & $(0.029)$ & $22.0 \%$ & $(0.050)$ & $21.7 \%$ & $(0.042)$ & $18.7 \%$ & $(0.044)$ \\
\hline Asalariados de PE & $19.7 \%$ & $(0.016)$ & $4.4 \%$ & $(0.008)$ & $2.7 \%$ & $(0.008)$ & $2.2 \%$ & $(0.007)$ & $2.5 \%$ & $(0.006)$ & $56.7 \%$ & $(0.021)$ & $11.7 \%$ & $(0.013)$ \\
\hline Trabajadores independientes & $15.6 \%$ & $(0.015)$ & $3.0 \%$ & $(0.007)$ & $0.8 \%$ & $(0.003)$ & $0.8 \%$ & $(0.003)$ & $1.8 \%$ & $(0.005)$ & $8.8 \%$ & $(0.011)$ & $69.2 \%$ & $(0.018)$ \\
\hline Total & $41.2 \%$ & $(0.007)$ & $18.5 \%$ & $(0.006)$ & $6.1 \%$ & $(0.004)$ & $2.0 \%$ & $(0.002)$ & $2.3 \%$ & $(0.002)$ & $14.2 \%$ & $(0.005)$ & $15.8 \%$ & $(0.005)$ \\
\hline
\end{tabular}

Fuente: Elaborado a partir de los microdatos de la EPH.

Nota: Entre paréntesis se presentan los errores estándares de las tasas de transición estimadas. 
Las probabilidades de transitar hacia los mejores empleos considerados (puestos AFSD) son marcadamente más bajas entre los AICD (menores al 7\%) que en el caso de los AISD. En cambio, la tasa de entrada hacia empleos AFCD son relativamente similares entre los AICD ( $9,7 \%$ en promedio) y AISD ( $9,2 \%$ en promedio). Además, las probabilidades de realizar un ascenso en términos de calidad del empleo son escasas para este grupo de asalariados. La entrada a puestos AFCD, AFSD como AISD presentan bajas tasas de transición (menores al 12,4\%). Al tener en cuenta que la mayoría de los AI de las MGEySP tienen déficit en algún atributo de la calidad del empleo (Gráfico 1), la falta de acceso a empleos de mayor calidad entre los AICD resulta más relevante, pues implica que una gran proporción del total de los AI no puede insertarse en un empleo de mayor calidad. Esto sugiere que las barreras a la entrada son más altas cuanto más déficit de calidad del empleo presente el puesto de trabajo que ocupa el asalariado en las MGEySP.

Dado que las diferencias en las características individuales, familiares y laborales de los asalariados que trabajan en las MGEySP pueden traducirse en distintas probabilidades de transición para determinado grupo de trabajadores, se analizan a continuación los resultados obtenidos de la estimación del modelo Logit (Cuadro A9 a Cuadro A15). Los resultados de este ejercicio refuerzan las conclusiones previamente obtenidas en relación con las dificultades que enfrentan los asalariados informales, tanto los AICD como los AISD, para acceder a empleos de mayor calidad, ya sea AFSD como AFCD. En general, la tasa de transición hacia estos dos últimos empleos para un AISD o un AICD, con características promedios o que pertenece a alguno de los grupos definidos según su sexo, edad, nivel educativo y rama de actividad, no son estadísticamente diferentes de cero. De la misma manera, los coeficientes estimados del modelo Logit correspondiente a la tasa de transición desde un puesto AISD (o AICD) a un puesto AFSD muestran, en general, que varias de las características laborales e individuales no presentan efectos significativos sobre esas transiciones. Las bajas probabilidades de transición entre los AI hacia los mejores puestos (AFSD), independientemente de sus características personales, familiares y laborales, corroboran las conclusiones derivadas a partir de las brechas salariales observadas entre los puestos AICD (o AISD) y los AFSD referidas a la presencia de estos segmentos laborales en las MGEySP. Esto sugiere que la tasa de entrada a empleos de calidad no depende de dichas características de los AI, sino del segmento laboral en el que se encuentran ocupados.

De la misma manera, la evidencia indica que varias de las probabilidades predichas de transitar desde un puesto AICD a un puesto AISD no son estadísticamente significativas, salvo en 2012-2013. Y las probabilidades que resultan estadísticamente positivas, en general, son bajas y no presentan diferencias entre los grupos definidos según género, edad, nivel educativo, rama de actividad, la cantidad de menores de cinco años en el hogar y la jefatura de hogar. Asimismo, la mayoría de las variables incluidas en el modelo Logit estimado parecen no ser determinantes de este tipo de transición. Esto sugiere 
que el desplazamiento de un puesto hacia el otro depende, en mayor medida, de la estructura del mercado de trabajo en las MGEySP que, conforme con la evidencia del aparato anterior, presenta barreras a la entrada a determinados puestos de trabajo dada la segmentación existente entre el conjunto de asalariados. En cambio, los AFCD con características promedios presentan las probabilidades predichas más altas de ingresar a puestos de calidad, es decir a los empleos AFSD. En general, cuanto mayor es el nivel educativo y la edad de los AFCD, más alta es su probabilidad de ingresar a puestos AFSD. También se observa, entre los AFCD, que las mujeres, los que son jefes de hogar y los que se desempeñan en el sector de servicios tienen más probabilidades de ingresar a mejores puestos que los varones y los que se encuentran ocupados en otra rama de actividad. Asimismo, los coeficientes del modelo Logit también indican que los atributos personales, familiares y laborales de los asalariados formales parecen jugar un cierto rol en las probabilidades de ingresar a puestos de trabajo sin ningún déficit. De manera que la evidencia de segmentación laboral entre ambos segmentos AFSD y AFCD es corroborada parcialmente, pues si bien existe una brecha salarial estadísticamente significativa, también se observan altas probabilidades de transitar desde un puesto hacia el otro, particularmente entre los que presentan determinadas características.

Por lo tanto, a partir de todos los resultados obtenidos se concluye que las transiciones hacia empleos de mayor calidad, ya sea AFCD o AFSD, entre los asalariados informales (ya sea AICD o AISD) resultan poco frecuentes. En cambio, una proporción considerable de AFCD logra acceder a puestos formales sin déficit de calidad (AFSD). Además, estas probabilidades crecen para aquellos que cuentan con un alto nivel educativo y calificación laboral. No obstante, cuando se corrigen dichas tasas de transición por la cantidad de puestos vacantes, los resultados indican que la intensidad de dichos flujos son relativamente bajos en comparación con los que surgirían si los AFCD se movieran libremente hacia puestos AFSD.

\section{CONCLUSIONES}

El objetivo de este artículo consiste en investigar si la heterogeneidad laboral presente en las MGEySP, durante 1995-2014, pudo haber generado una segmentación más compleja que la relacionada con la existencia de trabajadores formales e informales. Si bien estas empresas suelen incluirse como parte del sector formal de la economía, la evidencia encontrada contradice en varios aspectos los supuestos tradicionalmente realizados en la literatura, respecto a que las condiciones laborales allí ofrecidas son homogéneas y a que, por tanto, su funcionamiento es acorde a un mercado de trabajo competitivo.

La evidencia indica que el mercado de trabajo de las MGEySP lejos de presentar condiciones laborales homogéneas y funcionar acorde a un modelo competitivo, se encuentra segmentado porque existen puestos de trabajo de distinta calidad. En esta heterogeneidad de las condiciones laborales, la informalidad, la sobreocupación, el trabajo a tiempo 
parcial involuntario, el contrato de trabajo temporal y la insatisfacción laboral juegan un rol central. Atendiendo a la heterogeneidad de las condiciones de trabajo se identifican cuatro categorías de empleo, dos dentro de los asalariados formales ( $\mathrm{AF}$ con déficit y AF sin déficit de calidad) y otras dos dentro de los asalariados informales (AI con déficit y AI sin déficit de calidad). Estas categorías laborales constituyen una nueva clasificación del empleo asalariado no considerada hasta el momento por los estudios sobre el tema y, en consecuencia, también permiten determinar, mediante distintas y novedosas hipótesis de segmentación, si existe una estructura más compleja y particular en las MGEySP más allá de la estudiada generalmente en la literatura entre puestos de trabajo formales e informales. Por medio de la estimación de brechas salariales como de tasas brutas y condicionadas de transición se evalúa empíricamente la validez de cada una de las hipótesis de segmentación formuladas. Así, pues, los resultados obtenidos confirman la presencia de segmentos definidos en función de las cuatro categorías de empleo analizadas. En particular se observa que la segmentación laboral se produce con mayor intensidad entre los empleos formales e informales y en menor medida dentro de cada grupo. De modo que tanto la informalidad como los déficits en los otros atributos de la calidad del empleo son los fenómenos asociados con la segmentación del mercado de trabajo de las MGEySP, aunque el primero en mayor medida que el segundo. Esto último cuestiona varios estudios disponibles, según los cuales la segmentación laboral en los países en desarrollo se produce exclusivamente como consecuencia del empleo informal o dentro del sector informal ${ }^{21}$.

En síntesis, el mercado de trabajo de las MGEySP en Argentina presenta condiciones laborales heterogéneas y una estructura compleja que parece cambiar con determinadas fases del ciclo económico, políticas de comercio exterior y el contexto institucional. Asimismo tanto la evolución de las diferencias salariales como de los patrones de movilidad sugieren que estos factores macroeconómicos e institucionales podrían tener efectos sobre los fenómenos que producen la segmentación laboral observada en las MGEySP. Dadas las consecuencias económicas y sociales en términos de bienestar general e individual que tiene un mercado de trabajo segmentado, las políticas públicas deberían buscar reducir los distintos déficits de calidad del empleo presentes en las MGEySP, principalmente al tratarse de un mercado que contiene la mayor parte de la fuerza laboral argentina. Con el objetivo de analizar con más detenimiento esto último, en otra investigación se examinará como la tasa de informalidad laboral y los déficits en los otros atributos de la calidad del empleo que se encuentran asociados con los segmentos encontrados en las MGEySP responden frente a determinados contextos macroeconómicos y regulaciones laborales.

\footnotetext{
${ }^{21}$ Algunos de estos estudios son Alzúa (2008); Maurizio (2012); Günther y Launov (2012); entre otros.
} 


\begin{abstract}
ANEXO
Cuadro A1. Criterios de armonización implementados entre la modalidad puntual y continua de la EPH
\end{abstract}

\begin{tabular}{llll}
\hline $\begin{array}{l}\text { Aspectos captados } \\
\text { en forma diferenciada }\end{array}$ & \multicolumn{1}{c}{ EPH Continua (EPHC) } & EPH puntual (EPHP) & Criterios de armonización \\
\hline $\begin{array}{l}\text { Trabajadores del } \\
\text { servicio doméstico }\end{array}$ & $\begin{array}{l}\text { Los ocupados en el servicio } \\
\text { doméstico se clasifican por } \\
\text { definición como asalariados }\end{array}$ & $\begin{array}{l}\text { Los ocupados en el servicio } \\
\text { doméstico se clasifican de } \\
\text { acuerdo a la autoidentificación } \\
\text { del entrevistado }\end{array}$ & $\begin{array}{l}\text { Se incluye en la EPHP a los } \\
\text { trabajadores del servicio } \\
\text { doméstico como asalariados }\end{array}$ \\
$\begin{array}{l}\text { Trabajadores por } \\
\text { cuenta propia que } \\
\text { trabajan para un } \\
\text { solo cliente }\end{array}$ & $\begin{array}{l}\text { Los ocupados que delcaran } \\
\text { trabajar por cuenta propia para un } \\
\text { solo cliente, se clasifican por } \\
\text { definición como asalariados }\end{array}$ & $\begin{array}{l}\text { Los ocupados que delcaran } \\
\text { trabajar por cuenta propia } \\
\text { para un solo cliente, se } \\
\text { clasifican como cuenta propias }\end{array}$ & $\begin{array}{l}\text { Se incluye en la EPHP a los } \\
\text { trabajadores por cuenta propias } \\
\text { que declaran trabajar para } \\
\text { un solo cliente como asalariados }\end{array}$ \\
$\begin{array}{l}\text { Trabajadores en } \\
\text { relación de } \\
\text { dependencia que } \\
\text { no perciben salario }\end{array}$ & $\begin{array}{l}\text { Los trabajadores en relación de } \\
\text { dependencia sin ingresos salariales } \\
\text { se clasifican como asalariados }\end{array}$ & $\begin{array}{l}\text { Los trabajadores en relación } \\
\text { de dependencia sin ingresos } \\
\text { salariales se clasifican como } \\
\text { trabajadores sin salarios }\end{array}$ & $\begin{array}{l}\text { Se excluye de la EPHC a los } \\
\text { trabajadores en relación de } \\
\text { dependencia que no perciben } \\
\text { salario }\end{array}$ \\
\hline
\end{tabular}

Fuente: Elaborado a partir de Roca et al. (2006).

Cuadro A2. Cantidad de observaciones y porcentaje de desgranamiento en las bases de datos construidas para estimar las brechas salariales y los patrones de movilidad laboral en las MGEySP, 1996-2013.

\begin{tabular}{lccccc}
\hline \multicolumn{2}{c}{ Brechas salariales } & \multicolumn{2}{c}{ Patrones de movilidad } \\
\hline \hline Paneles Observaciones & $\begin{array}{c}\text { Desgranamiento } \\
\text { (en \%) }\end{array}$ & Paneles Observaciones & $\begin{array}{c}\text { Desgranamiento } \\
\text { (en \%) }\end{array}$ \\
\hline $1996-1997$ & 32,058 & $9.7 \%$ & $1996-1997$ & 42,153 & $0.5 \%$ \\
$2001-2002$ & 24,900 & $8.9 \%$ & $2001-2002$ & 31,481 & $0.4 \%$ \\
$2006-2007$ & 13,542 & $7.9 \%$ & $2006-2007$ & 18,053 & $5.2 \%$ \\
$2012-2013$ & 16,058 & $6.9 \%$ & $2012-2013$ & 21,305 & $0.0 \%$ \\
\hline
\end{tabular}

Fuente: Elaborado a partir de los microdatos de la EPH. 


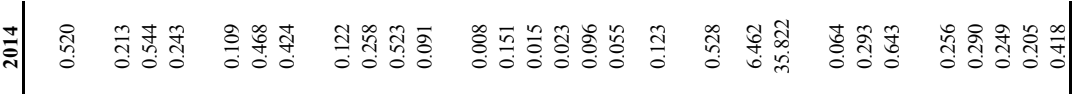

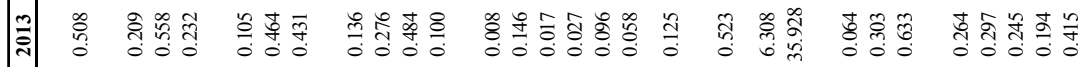

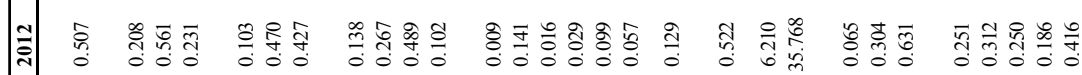

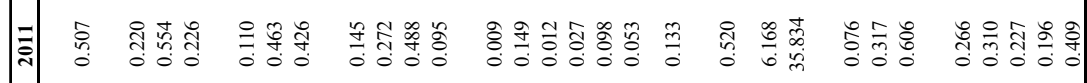

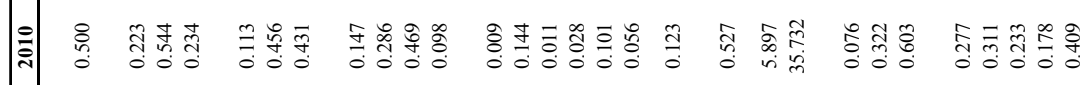

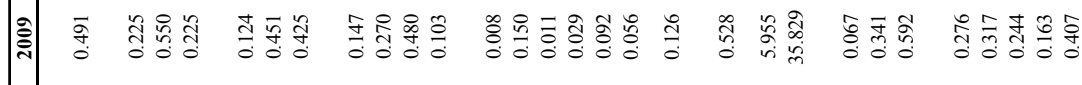

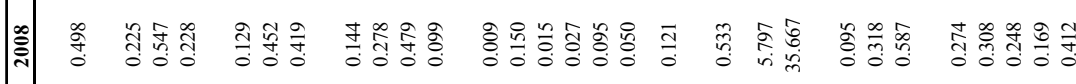

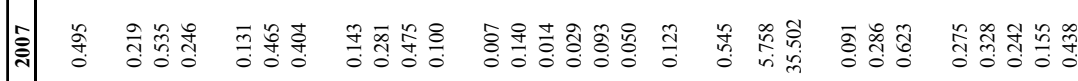

논

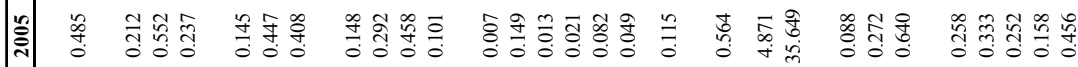

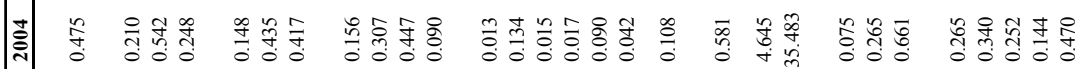

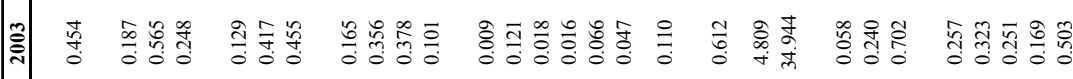

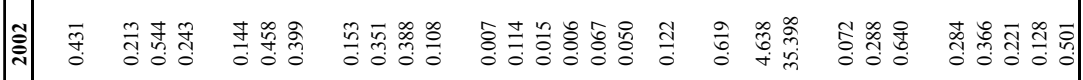

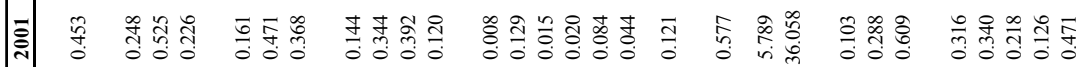

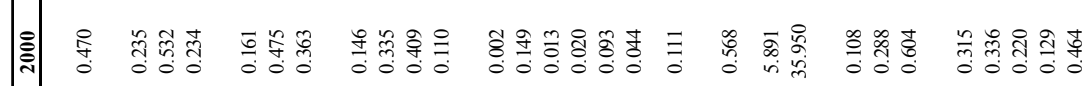

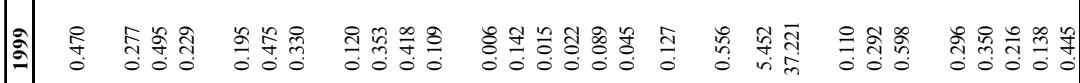

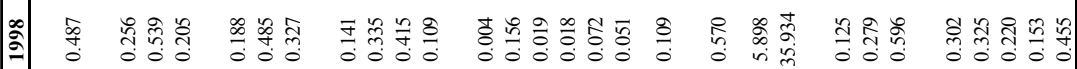

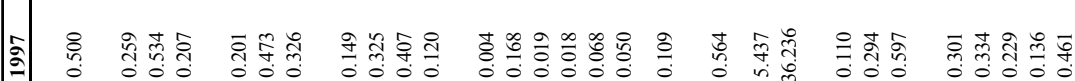

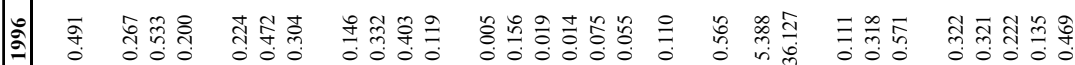

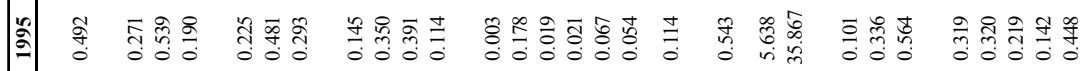




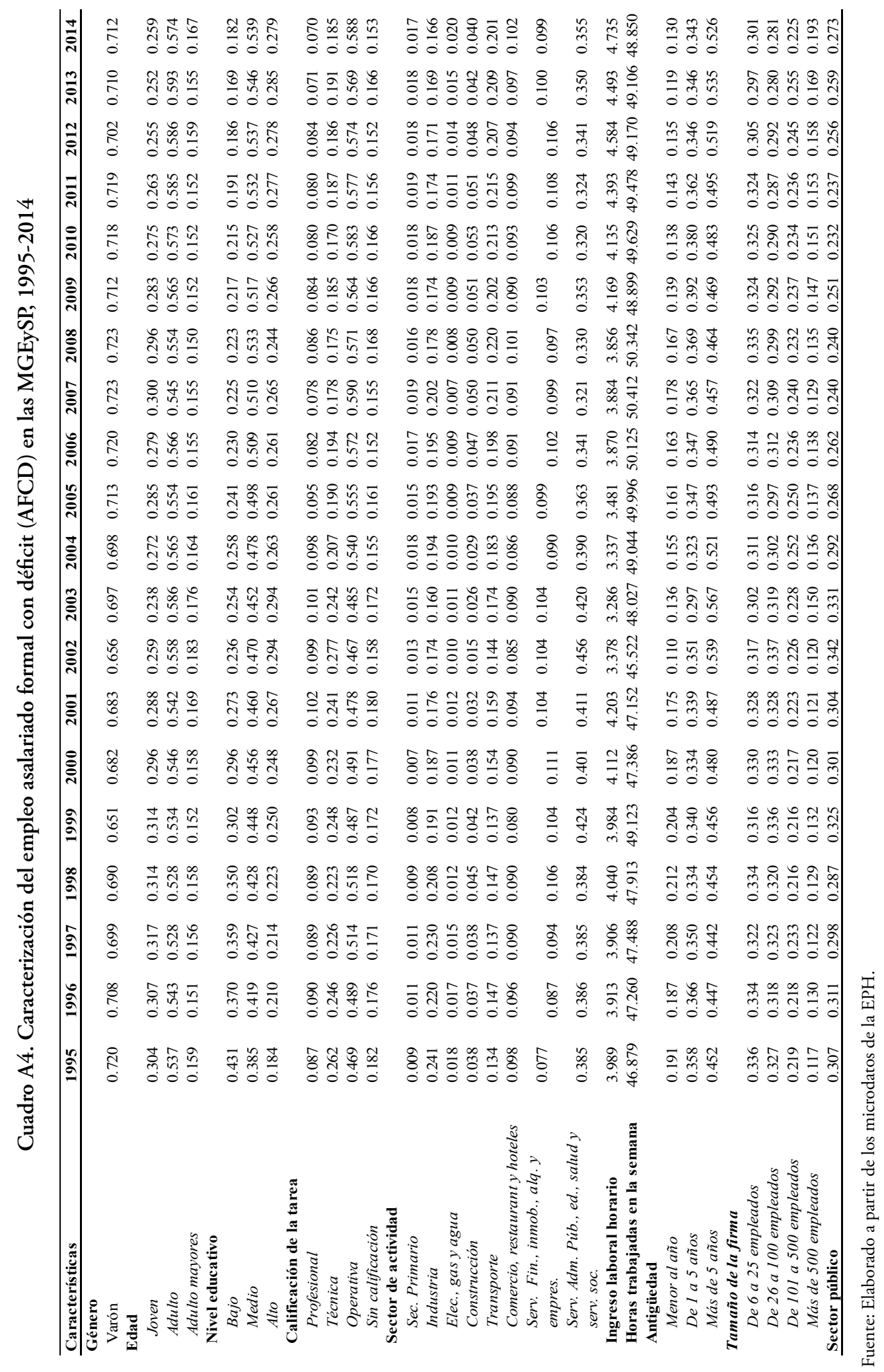




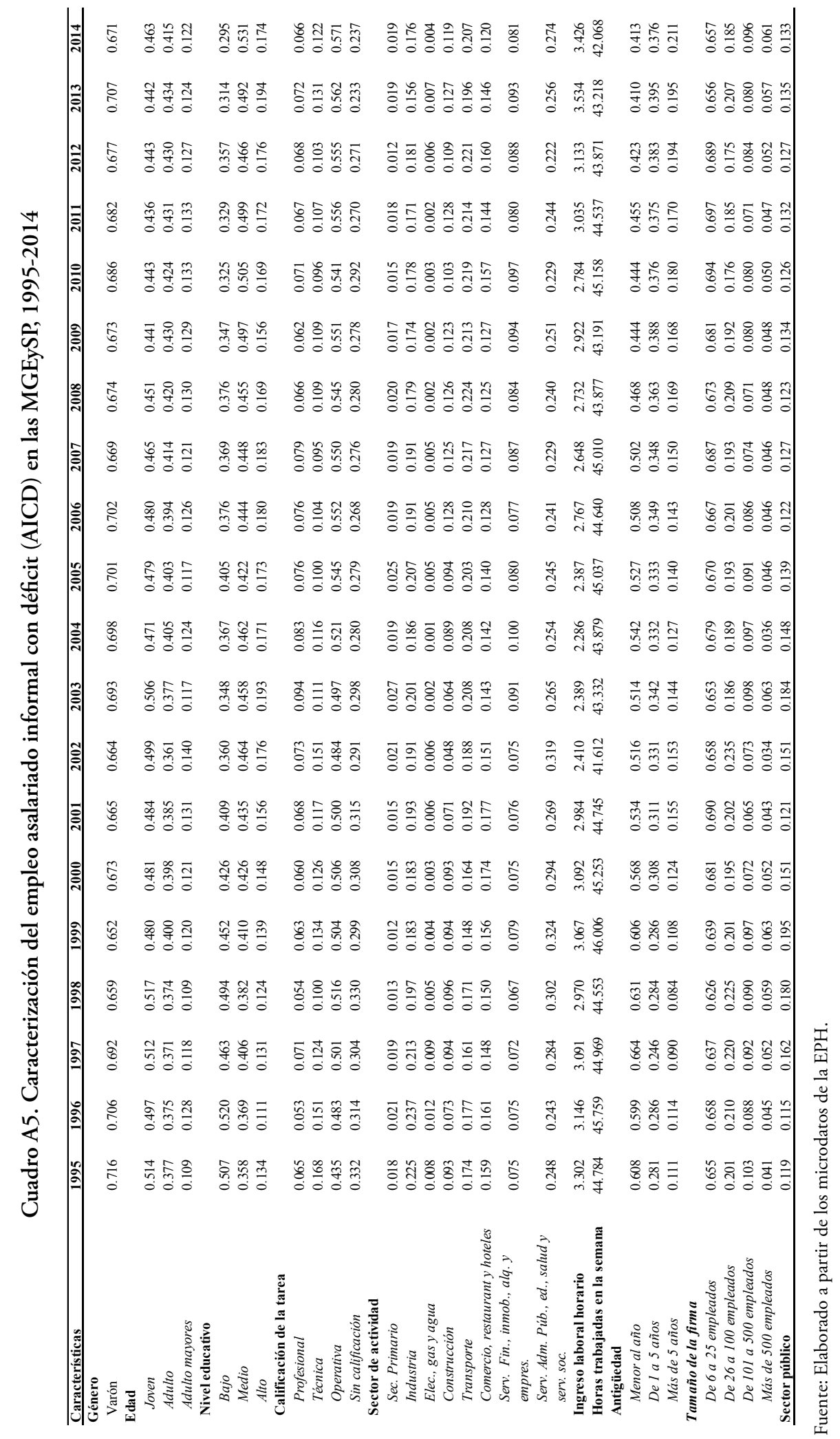




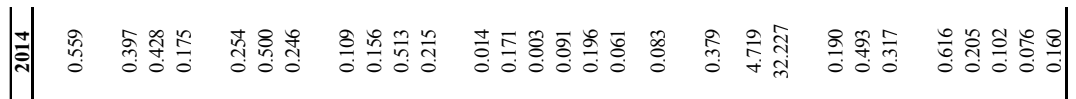

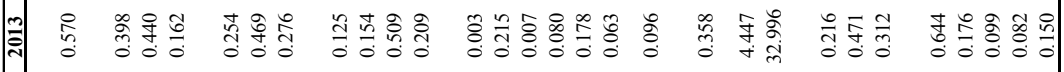

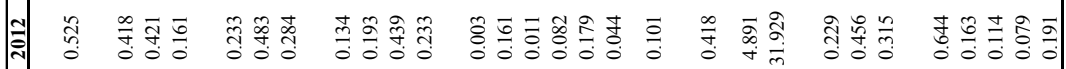

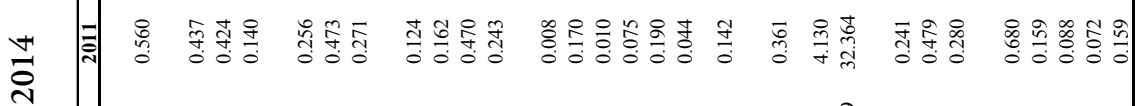

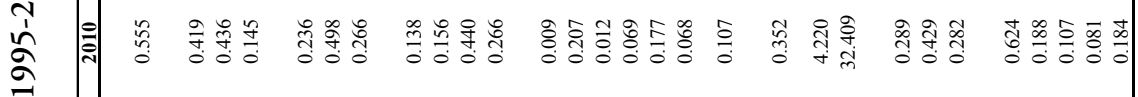

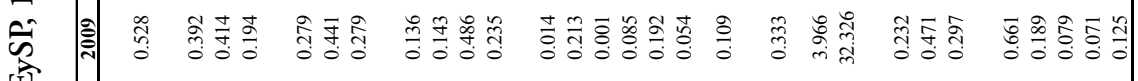

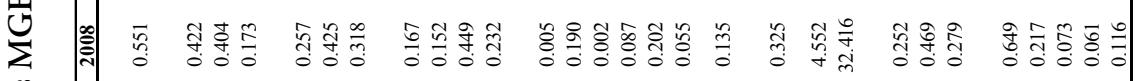

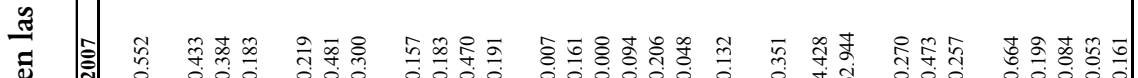

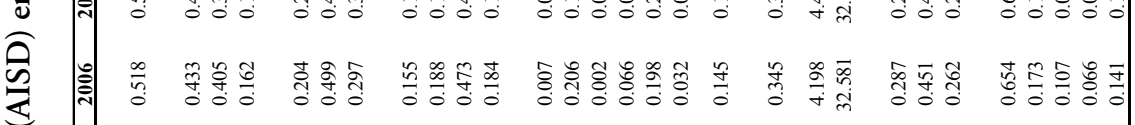

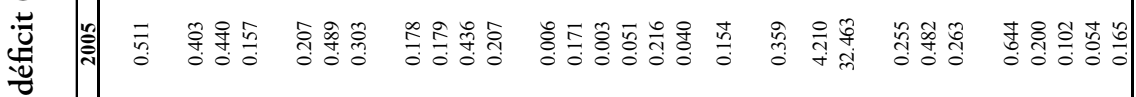

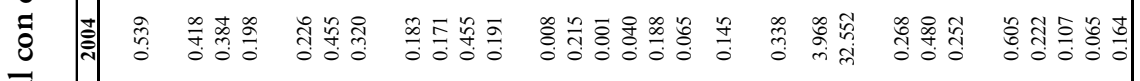

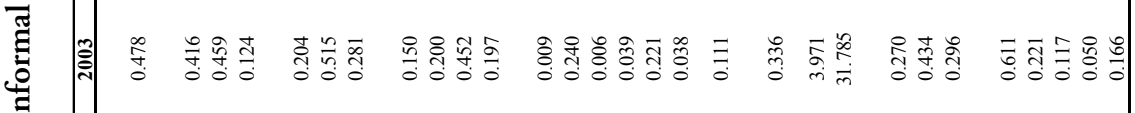

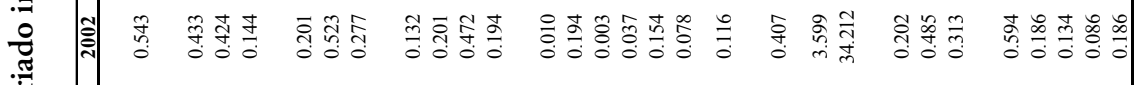

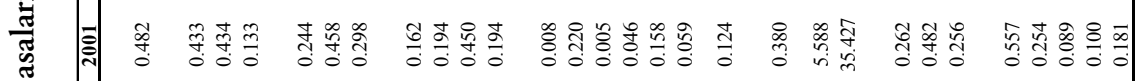

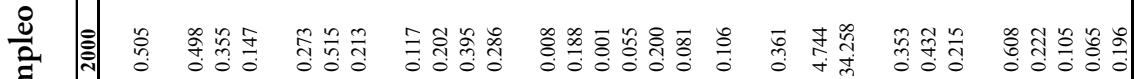

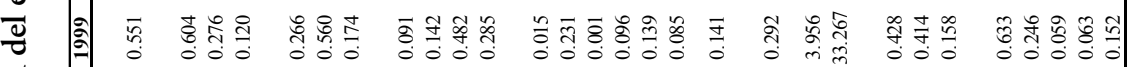

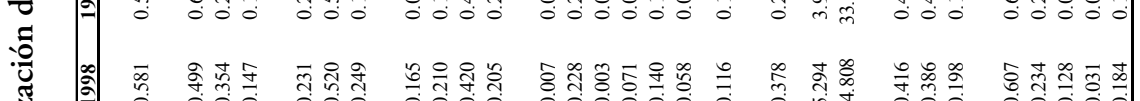

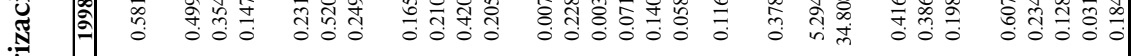

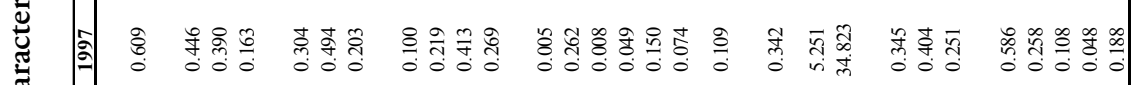

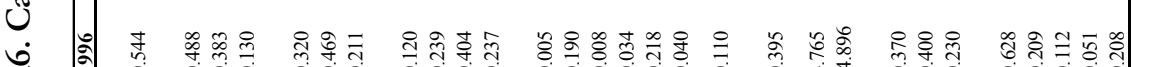

र

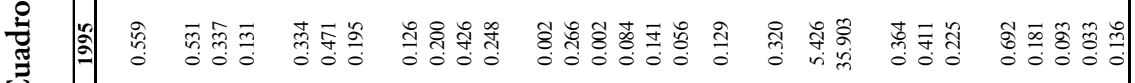

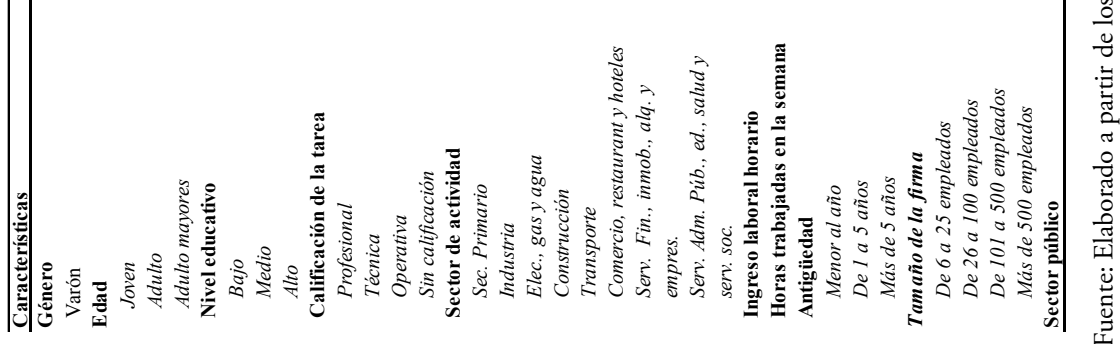


Cuadro A7. Brechas salariales estimadas a partir del modelo de efectos fijos, 1996-2014

\begin{tabular}{|c|c|c|c|c|}
\hline Transiciones & 1996-1997 & 2001-2002 & 2006-2007 & 2012-2013 \\
\hline \multirow[t]{2}{*}{$\mathrm{AI} \leftrightarrow \mathrm{AF}$} & $0.1768 * * *$ & $0.0884 * * *$ & $0.1625 * * *$ & $0.1800^{* * *}$ \\
\hline & $(0.0170)$ & $(0.0216)$ & $(0.0365)$ & $(0.0327)$ \\
\hline Observaciones & 9,302 & 6,407 & 3,907 & 4,864 \\
\hline \multirow[t]{2}{*}{$\mathrm{ACD} \leftrightarrow \mathrm{ASD}$} & $0.0475 * * *$ & $0.0683 * * *$ & $0.0856 * * *$ & $0.0852 * * *$ \\
\hline & $(0.0093)$ & $(0.0108)$ & $(0.0202)$ & $(0.0181)$ \\
\hline Observaciones & 9,302 & 6,407 & 3,907 & 4,864 \\
\hline \multirow[t]{2}{*}{$\mathrm{AFCD} \leftrightarrow \mathrm{AFSD}$} & $0.0362 * * *$ & $0.0605 * * *$ & $0.0745 * * *$ & $0.0709 * * *$ \\
\hline & $(0.0096)$ & $(0.0112)$ & $(0.0212)$ & $(0.0193)$ \\
\hline Observaciones & 9,302 & 6,407 & 3,907 & 4,864 \\
\hline \multirow[t]{2}{*}{ AICD $\leftrightarrow$ AISD } & $0.1875 * * *$ & $0.1599 * * *$ & $0.1632 * * *$ & $0.1671 * * *$ \\
\hline & $(0.0316)$ & $(0.0352)$ & $(0.0488)$ & $(0.0431)$ \\
\hline Observaciones & 9,302 & 6,407 & 3,907 & 4,864 \\
\hline \multirow[t]{2}{*}{$\mathrm{RA} \leftrightarrow \mathrm{AFSD}$} & $0.0470 * * *$ & $0.0651 * * *$ & $0.0987 * * *$ & $0.0987 * * *$ \\
\hline & $(0.0096)$ & $(0.0110)$ & $(0.0206)$ & $(0.0183)$ \\
\hline \multirow[t]{2}{*}{$\mathrm{AICD} \leftrightarrow \mathrm{RA}$} & $0.2247 * * *$ & $0.1309 * * *$ & $0.1865 * * *$ & $0.2024 * * *$ \\
\hline & $(0.0171)$ & $(0.0208)$ & $(0.0354)$ & $(0.0325)$ \\
\hline Observaciones & 9,316 & 6,413 & 3,980 & 4,956 \\
\hline \multirow[t]{2}{*}{$\mathrm{RA} \leftrightarrow \mathrm{AFCD}$} & 0.0078 & $0.0365 * * *$ & $0.0393 *$ & 0.0278 \\
\hline & $(0.0090)$ & $(0.0107)$ & $(0.0208)$ & $(0.0185)$ \\
\hline \multirow[t]{2}{*}{$\mathrm{AISD} \leftrightarrow \mathrm{RA}$} & $0.0660 * *$ & $0.0986 * * *$ & 0.0595 & 0.0281 \\
\hline & $(0.0306)$ & $(0.0343)$ & $(0.0443)$ & $(0.0376)$ \\
\hline Observaciones & 9,316 & 6,413 & 3,980 & 4,956 \\
\hline \multirow[t]{2}{*}{$\mathrm{AICD} \leftrightarrow \mathrm{AF}$} & $0.2139 * * *$ & $0.1256 * * *$ & $0.2597 * * *$ & $0.2454 * * *$ \\
\hline & $(0.0179)$ & $(0.0223)$ & $(0.0397)$ & $(0.0364)$ \\
\hline \multirow[t]{2}{*}{$\mathrm{AISD} \leftrightarrow \mathrm{AF}$} & 0.031 & 0.0239 & $0.0960 * *$ & $0.0887 * *$ \\
\hline & $(0.0311)$ & $(0.0366)$ & $(0.0484)$ & $(0.0415)$ \\
\hline Observaciones & 9,303 & 6,409 & 3,921 & 4,895 \\
\hline \multirow[t]{2}{*}{$\mathrm{AI} \leftrightarrow \mathrm{AFCD}$} & $0.1721 * * *$ & $0.0812 * * *$ & $0.1459 * * *$ & $0.1676^{* * *}$ \\
\hline & $(0.0172)$ & $(0.0219)$ & $(0.0376)$ & $(0.0335)$ \\
\hline \multirow[t]{2}{*}{$\mathrm{AI} \leftrightarrow \mathrm{AFSD}$} & $0.2061 * * *$ & $0.1389 * * *$ & $0.2118 * * *$ & $0.2350 * * *$ \\
\hline & $(0.0184)$ & $(0.0227)$ & $(0.0374)$ & $(0.0336)$ \\
\hline Observaciones & 9,302 & 6,407 & 3,966 & 4,925 \\
\hline \multirow[t]{2}{*}{$\mathrm{AICD} \leftrightarrow \mathrm{AFCD}$} & $0.1972 * * *$ & $0.1166^{* * *}$ & $0.1777 * * *$ & $0.1849 * * *$ \\
\hline & $(0.0223)$ & $(0.0288)$ & $(0.0570)$ & $(0.0483)$ \\
\hline Observaciones & 5,601 & 4,023 & 1,903 & 2,044 \\
\hline \multirow[t]{2}{*}{$\mathrm{AICD} \leftrightarrow \mathrm{AFSD}$} & $0.2883 * * *$ & $0.2176^{* * *}$ & $0.2887 * * *$ & $0.1898 * * *$ \\
\hline & $(0.0340)$ & $(0.0400)$ & $(0.0781)$ & $(0.0573)$ \\
\hline Observaciones & 4,767 & 3,229 & 2,358 & 3,093 \\
\hline \multirow[t]{2}{*}{$\mathrm{AISD} \leftrightarrow \mathrm{AFSD}$} & $0.1415 * * *$ & 0.0746 & $0.1120^{*}$ & 0.0551 \\
\hline & $(0.0455)$ & $(0.0550)$ & $(0.0632)$ & $(0.0654)$ \\
\hline Observaciones & 3,701 & 2,384 & 2,004 & 2,820 \\
\hline \multirow[t]{2}{*}{$\mathrm{AISD} \leftrightarrow \mathrm{AFCD}$} & $0.1064 * *$ & 0.0116 & $0.2574 * *$ & $0.3235 * * *$ \\
\hline & $(0.0426)$ & $(0.0628)$ & $(0.1183)$ & $(0.0760)$ \\
\hline Observaciones & 4,535 & 3,178 & 1,549 & 1,771 \\
\hline
\end{tabular}

Fuente: Elaborado a partir de los microdatos de la EPH.

Nota: Entre paréntesis se reportan los errores estándares. $\leftrightarrow$ denota transiciones o trayectorias entre categorías laborales. RA: resto de los asalariados no considerados en la categoría de comparación. 
Cuadro A8. Descomposición de los cambios temporales de las brechas salariales estimadas entre los segmentos laborales analizados, 1995-2013

\begin{tabular}{|c|c|c|c|c|c|c|c|}
\hline Segmentos & $\mathbf{A I} \leftrightarrow \mathbf{A F}$ & ACD $\leftrightarrow$ ASD & AFCD $\leftrightarrow$ AFSD & AICD $\leftrightarrow$ AISD & RA $\leftrightarrow$ AFSD & $\mathrm{AICD} \leftrightarrow \mathrm{RA}$ & $\mathrm{AICD} \leftrightarrow \mathrm{AFCD}$ \\
\hline Parte explicada & $8.50 \%$ & $-17.99 \%$ & $-8.09 \%$ & $-9.25 \%$ & $-15.97 \%$ & $-0.02 \%$ & $-4.98 \%$ \\
\hline \multicolumn{8}{|l|}{ Descomposición de la parte explicada } \\
\hline Efecto cantidad $(Q)$ & $-4.93 \%$ & $6.73 \%$ & $-0.29 \%$ & $4.26 \%$ & $6.33 \%$ & $-0.38 \%$ & $-1.14 \%$ \\
\hline Efecto precio $(P)$ & $24.18 \%$ & $-35.29 \%$ & $-26.35 \%$ & $23.91 \%$ & $-31.13 \%$ & $22.24 \%$ & $10.21 \%$ \\
\hline Diferencia total 2001-2002 y 2006-2007 & $28.14 \%$ & $24.72 \%$ & $13.20 \%$ & $52.12 \%$ & $18.19 \%$ & $32.61 \%$ & $23.91 \%$ \\
\hline Parte explicada & $-24.58 \%$ & $-41.82 \%$ & $-36.93 \%$ & $-11.22 \%$ & $-45.59 \%$ & $-54.98 \%$ & $-23.67 \%$ \\
\hline Parte no explicada & $52.72 \%$ & $66.55 \%$ & $50.13 \%$ & $63.34 \%$ & $63.78 \%$ & $87.59 \%$ & $47.58 \%$ \\
\hline \multicolumn{8}{|l|}{ Descomposición de la parte explicada } \\
\hline Efecto cantidad $(Q)$ & $31.06 \%$ & $21.11 \%$ & $13.99 \%$ & $38.22 \%$ & $19.44 \%$ & $39.79 \%$ & $27.36 \%$ \\
\hline Efecto precio $(P)$ & $-17.53 \%$ & $-36.79 \%$ & $-33.46 \%$ & $-7.22 \%$ & $-38.47 \%$ & $-50.07 \%$ & $-30.76 \%$ \\
\hline \multicolumn{8}{|l|}{ Descomposición de la parte explicada } \\
\hline Efecto cantidad $(Q)$ & $-5.07 \%$ & $7.06 \%$ & $1.81 \%$ & $22.47 \%$ & $0.27 \%$ & $-6.45 \%$ & $26.97 \%$ \\
\hline Efecto precio $(P)$ & $-24.54 \%$ & $31.14 \%$ & $3.18 \%$ & $19.14 \%$ & $-12.82 \%$ & $-19.99 \%$ & $64.70 \%$ \\
\hline Efecto interacción $(Q P)$ & $5.99 \%$ & $-5.04 \%$ & $8.56 \%$ & $-65.56 \%$ & $5.37 \%$ & $4.13 \%$ & $-40.98 \%$ \\
\hline
\end{tabular}

\begin{tabular}{|c|c|c|c|c|c|c|c|}
\hline Segmentos & AICD $\leftrightarrow$ AFSD & AISD $\leftrightarrow$ AFSD & AISD $\leftrightarrow$ AFCD & $\mathbf{A I C D} \leftrightarrow \mathbf{A F}$ & $\mathbf{A I S D} \leftrightarrow \mathbf{A F}$ & $\mathbf{A I} \leftrightarrow \mathbf{A F C D}$ & $\mathbf{A I} \leftrightarrow \mathbf{A F S D}$ \\
\hline Cambio entre 1996-1997 y 2001-2002 & $-47.57 \%$ & $-5.28 \%$ & $0.68 \%$ & $-44.14 \%$ & $-1.85 \%$ & $-38.85 \%$ & $-44.81 \%$ \\
\hline Parte explicada & $7.63 \%$ & $118.01 \%$ & $93.00 \%$ & $0.32 \%$ & $103.59 \%$ & $3.95 \%$ & $21.51 \%$ \\
\hline Parte no explicada & $-55.20 \%$ & $-123.29 \%$ & $-92.32 \%$ & $-44.46 \%$ & $-105.44 \%$ & $-42.80 \%$ & $-66.32 \%$ \\
\hline \multicolumn{8}{|l|}{ Descomposición de la parte explicada } \\
\hline Efecto cantidad $(Q)$ & $0.25 \%$ & $26.55 \%$ & $64.27 \%$ & $-0.47 \%$ & $49.06 \%$ & $-9.48 \%$ & $-4.18 \%$ \\
\hline Efecto precio $(P)$ & $40.13 \%$ & $34.89 \%$ & $-23.51 \%$ & $22.20 \%$ & $-0.08 \%$ & $12.08 \%$ & $47.26 \%$ \\
\hline Efecto interacción $(Q P)$ & $-32.75 \%$ & $56.57 \%$ & $52.24 \%$ & $-21.41 \%$ & $54.61 \%$ & $1.35 \%$ & $-21.56 \%$ \\
\hline Diferencia total 2001-2002 y 2006-2007 & $37.11 \%$ & $-15.02 \%$ & $-28.21 \%$ & $29.69 \%$ & $-22.43 \%$ & $20.74 \%$ & $33.94 \%$ \\
\hline Parte explicada & $-94.17 \%$ & $-215.52 \%$ & $-94.94 \%$ & $-59.47 \%$ & $-156.73 \%$ & $-13.85 \%$ & $-86.82 \%$ \\
\hline Parte no explicada & $131.28 \%$ & $200.51 \%$ & $66.73 \%$ & $89.17 \%$ & $134.30 \%$ & $34.60 \%$ & $120.76 \%$ \\
\hline \multicolumn{8}{|l|}{ Descomposición de la parte explicada } \\
\hline Efecto cantidad $(Q)$ & $40.08 \%$ & $-7.58 \%$ & $-37.72 \%$ & $39.40 \%$ & $-13.25 \%$ & $17.87 \%$ & $30.83 \%$ \\
\hline Efecto precio $(P)$ & $-80.72 \%$ & $-181.31 \%$ & $-105.11 \%$ & $-51.33 \%$ & $-136.51 \%$ & $-10.88 \%$ & $-65.10 \%$ \\
\hline Efecto interacción $(Q P)$ & $-53.54 \%$ & $-26.63 \%$ & $47.88 \%$ & $-47.54 \%$ & $-6.97 \%$ & $-20.84 \%$ & $-52.55 \%$ \\
\hline Diferencia total $2006-2007$ y 2012-2013 & $-3.96 \%$ & $-0.75 \%$ & $5.47 \%$ & $-1.54 \%$ & $-1.68 \%$ & $6.96 \%$ & $0.74 \%$ \\
\hline Parte explicada & $119.30 \%$ & $83.77 \%$ & $78.59 \%$ & $92.16 \%$ & $-78.83 \%$ & $21.12 \%$ & $80.78 \%$ \\
\hline Parte no explicada & $-123.27 \%$ & $-84.52 \%$ & $-73.12 \%$ & $-93.70 \%$ & $77.15 \%$ & $-14.16 \%$ & $-80.04 \%$ \\
\hline \multicolumn{8}{|l|}{ Descomposición de la parte explicada } \\
\hline Efecto cantidad $(Q)$ & $27.23 \%$ & $58.75 \%$ & $65.67 \%$ & $24.44 \%$ & $-14.60 \%$ & $20.40 \%$ & $23.55 \%$ \\
\hline Efecto precio $(P)$ & $142.75 \%$ & $82.38 \%$ & $42.70 \%$ & $109.71 \%$ & $-19.89 \%$ & $27.56 \%$ & $82.42 \%$ \\
\hline Efecto interacción $(Q P)$ & $-50.68 \%$ & $-57.36 \%$ & $-29.78 \%$ & $-41.99 \%$ & $-44.34 \%$ & $-26.85 \%$ & $-25.19 \%$ \\
\hline
\end{tabular}

Fuente: Elaborado a partir de los microdatos de la EPH. 
Cuadro A9. Probabilidades de transición predichas a partir un modelo logit, 1996-2013

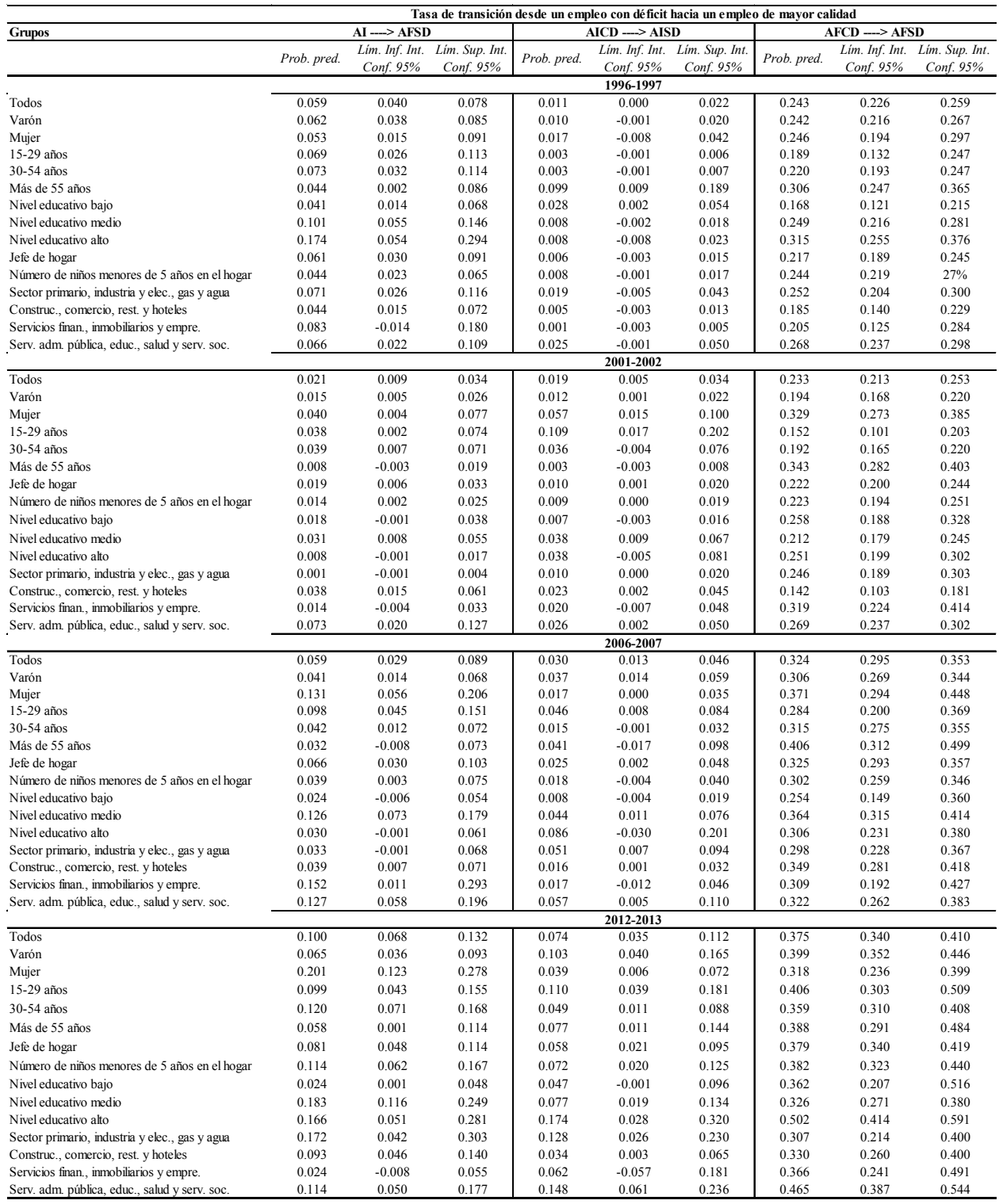

Fuente: Elaborado a partir de los microdatos de la EPH. 
Cuadro A10. Probabilidades de transición predichas a partir de un modelo Logit, 1996-2013

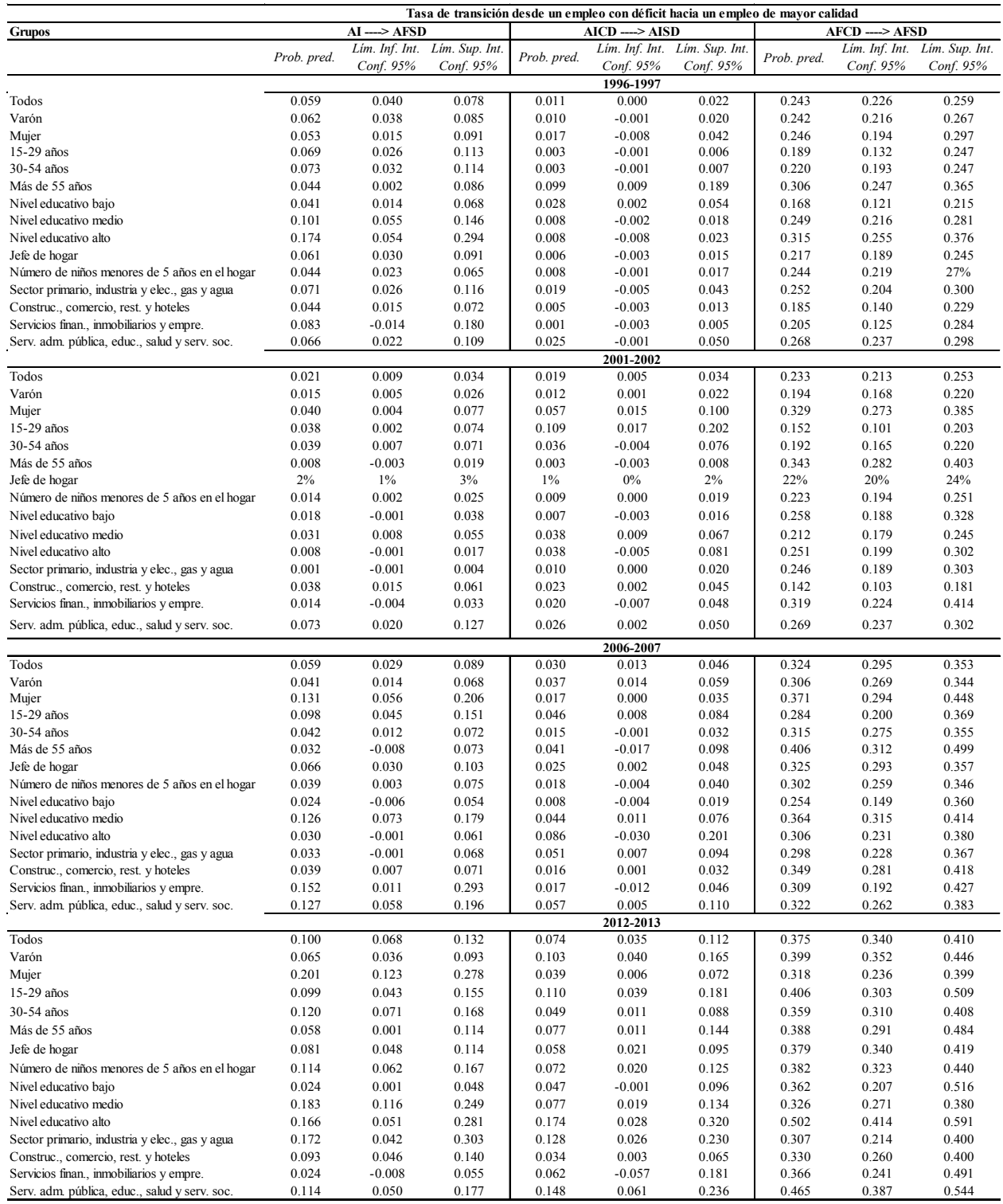

Fuente: Elaborado a partir de los microdatos de la EPH. 
Cuadro A11. Modelo Logit de la tasa de entrada a puestos de trabajo de calidad, 1996-1997

\begin{tabular}{|c|c|c|c|c|c|}
\hline Variables & AISD -->> AFSD & AICD $-\rightarrow$ AFSD & AI $\longrightarrow$ AFSD & AICD $\ldots$ AISD & AFCD $-->$ AFSD \\
\hline \multirow[t]{2}{*}{ Varón } & -0.5002 & 0.3591 & 0.0462 & -0.7954 & -0.1724 \\
\hline & $(0.5551)$ & $(0.7281)$ & $(0.4204)$ & $(0.7098)$ & $(0.1549)$ \\
\hline \multirow[t]{2}{*}{ Joven de 15 a 29 años } & 0.5026 & 0.8936 & 0.6660 & $-2.1496 * * *$ & -0.2628 \\
\hline & $(1.0322)$ & $(0.7736)$ & $(0.5643)$ & $(0.5811)$ & $(0.2183)$ \\
\hline \multirow[t]{2}{*}{ Adulto de edad central ( 30 a 49 años) } & 0.4552 & 1.1628 & 0.7773 & $-1.7946^{* * *}$ & $-0.3252 *$ \\
\hline & $(0.7595)$ & $(0.7580)$ & $(0.5157)$ & $(0.5928)$ & $(0.1676)$ \\
\hline \multirow[t]{2}{*}{ Nivel ed. bajo } & $-3.1521 * * *$ & $-2.0310 * * *$ & $-2.2042 * * *$ & -0.1510 & $-0.4051^{* *}$ \\
\hline & $(1.1937)$ & $(0.7041)$ & $(0.6214)$ & $(0.8804)$ & $(0.1971)$ \\
\hline \multirow[t]{2}{*}{ Nivel ed. medio } & -0.0497 & -0.8923 & -0.7161 & -0.1163 & $-0.3447 *$ \\
\hline & $(0.6755)$ & $(0.7106)$ & $(0.5439)$ & $(0.8190)$ & $(0.1789)$ \\
\hline \multirow[t]{2}{*}{ Calificados } & $-3.1272 * * *$ & 0.3349 & -0.6206 & $-1.4751^{*}$ & $0.4437 * *$ \\
\hline & $(0.9202)$ & $(0.4805)$ & $(0.4737)$ & $(0.8257)$ & $(0.1930)$ \\
\hline \multirow[t]{2}{*}{ Jefe de hogar } & $2.5338 * * *$ & $1.2043 *$ & $1.5429 * * *$ & -0.1397 & -0.3089 \\
\hline & $(0.6497)$ & $(0.6439)$ & $(0.4216)$ & $(0.5945)$ & $(0.1971)$ \\
\hline \multirow[t]{2}{*}{ Menores de cinco años en el hogar } & $-1.6699 * * *$ & $-0.6289^{*}$ & $-0.7325^{* * *}$ & $-0.5327 * *$ & -0.0062 \\
\hline & $(0.4839)$ & $(0.3701)$ & $(0.2599)$ & $(0.2368)$ & $(0.0971)$ \\
\hline \multirow[t]{2}{*}{ Menos de 1 año de antigüedad } & -0.0047 & 0.2248 & -0.2166 & 0.5864 & $-0.3913^{*}$ \\
\hline & $(0.6558)$ & $(0.5367)$ & $(0.3877)$ & $(0.6947)$ & $(0.2261)$ \\
\hline \multirow[t]{2}{*}{ Entre 1 a 5 años de antigüedad } & -0.8668 & -0.8267 & $-0.7399 *$ & 0.7952 & $-0.2688^{*}$ \\
\hline & $(0.6706)$ & $(0.6188)$ & $(0.3985)$ & $(0.7789)$ & $(0.1530)$ \\
\hline \multirow[t]{2}{*}{ Construc., comercio, rest. y hoteles } & -0.2601 & 0.3793 & 0.0414 & -0.3474 & -0.1031 \\
\hline & $(0.7645)$ & $(0.8689)$ & $(0.5292)$ & $(0.7102)$ & $(0.1693)$ \\
\hline \multirow[t]{2}{*}{ Servicios finan., inmobiliarios y empre. } & -1.3157 & -0.1159 & -0.4407 & $-1.6747^{*}$ & $-0.5059 * * *$ \\
\hline & $(0.8177)$ & $(0.9048)$ & $(0.5641)$ & $(0.9492)$ & $(0.1864)$ \\
\hline \multirow[t]{2}{*}{ Serv. adm. pública, educ., salud y serv. soc. } & 0.0438 & -0.1055 & 0.3960 & -2.2578 & -0.3885 \\
\hline & $(0.9578)$ & $(0.9161)$ & $(0.7309)$ & $(1.5978)$ & $(0.2671)$ \\
\hline \multirow[t]{2}{*}{ GBA } & $-5.8337 * * *$ & $-1.3426^{* *}$ & $-1.6919 * * *$ & 0.5398 & $0.3409 * *$ \\
\hline & $(1.2395)$ & $(0.6139)$ & $(0.5148)$ & $(0.6912)$ & $(0.1611)$ \\
\hline \multirow[t]{2}{*}{ NOA y NEA } & -1.4663 & -0.7111 & -0.3447 & 0.0964 & $0.5101 * * *$ \\
\hline & $(1.0859)$ & $(0.6689)$ & $(0.4534)$ & $(0.6647)$ & $(0.1416)$ \\
\hline \multirow[t]{2}{*}{ Cuyo } & $-2.9707 * *$ & -0.2655 & -0.5018 & $-1.7660^{*}$ & $0.4714^{* * *}$ \\
\hline & $(1.2030)$ & $(0.5444)$ & $(0.4173)$ & $(0.9679)$ & $(0.1395)$ \\
\hline \multirow[t]{2}{*}{ Medianas empresas } & $-2.9910^{* * * *}$ & $-1.5759^{*}$ & $-1.8587 * * *$ & -0.2724 & 0.2537 \\
\hline & $(0.9567)$ & $(0.8749)$ & $(0.5942)$ & $(1.3072)$ & $(0.2390)$ \\
\hline \multirow[t]{2}{*}{ Grandes empresas } & -0.7920 & $-1.4483^{* * *}$ & $-1.2557 * * *$ & -0.7004 & $0.2655^{*}$ \\
\hline & $(0.6194)$ & $(0.4669)$ & $(0.4203)$ & $(0.5469)$ & $(0.1377)$ \\
\hline \multirow[t]{2}{*}{ Ingreso laboral mensual } & $0.0011^{* *}$ & -0.0003 & -0.0001 & $0.0009 * *$ & 0.0000 \\
\hline & $(0.0005)$ & $(0.0003)$ & $(0.0002)$ & $(0.0004)$ & $(0.0001)$ \\
\hline \multirow[t]{2}{*}{ Constante } & $3.4472 *$ & -1.9795 & -0.3274 & 0.3299 & $-0.8788^{* *}$ \\
\hline & $(1.9521)$ & $(1.2683)$ & $(0.8810)$ & $(1.2002)$ & $(0.3550)$ \\
\hline Observaciones & 200 & 913 & 1,113 & 913 & 4,784 \\
\hline
\end{tabular}

Fuente: Elaborado a partir de los microdatos de la EPH.

Nota: Entre paréntesis se presentan los errores estándares. Tienen nivel educativo bajo los individuos con menos de secundario incompleto, nivel educativo medio, aquellos con secundario completo o universitario incompleto y nivel educativo alto, quienes completaron el nivel universitario. 
Cuadro A12. Modelo Logit de la tasa de entrada a puestos de trabajo de calidad, 2001-2002

\begin{tabular}{|c|c|c|c|c|c|}
\hline Variables & AISD $-->$ AFSD & AICD $-->$ AFSD & AI $\longrightarrow$ AFSD & AICD $-\rightarrow$ AISD & AFCD $\ldots$ AFSD \\
\hline \multirow[t]{2}{*}{ Varón } & $-3.4063 * * *$ & 0.8226 & -0.8409 & $-1.5578 * * *$ & $-0.9783 * * *$ \\
\hline & $(1.0358)$ & $(0.5532)$ & $(0.5220)$ & $(0.5455)$ & $(0.1517)$ \\
\hline \multirow[t]{2}{*}{ Joven de 15 a 29 años } & $2.8718^{*}$ & $1.9864 * *$ & 1.1728 & $3.4402 * * *$ & $-0.4269^{*}$ \\
\hline & $(1.5210)$ & $(1.0014)$ & $(0.7381)$ & $(0.9723)$ & $(0.2311)$ \\
\hline \multirow[t]{2}{*}{ Adulto de edad central ( 30 a 49 años) } & $3.2189 * *$ & $2.2087 * *$ & $1.3103^{*}$ & 1.3806 & $-0.5353 * * *$ \\
\hline & $(1.3621)$ & $(1.0133)$ & $(0.6996)$ & $(0.9931)$ & $(0.1667)$ \\
\hline \multirow[t]{2}{*}{ Nivel ed. bajo } & $3.4036 * *$ & -0.7130 & $1.3874 *$ & -0.7979 & -0.0484 \\
\hline & $(1.4277)$ & $(0.8012)$ & $(0.8375)$ & $(0.7236)$ & $(0.2026)$ \\
\hline \multirow[t]{2}{*}{ Nivel ed. medio } & $3.1317^{* * *}$ & 0.1262 & $1.2799 * *$ & -0.0295 & -0.2618 \\
\hline & $(1.1933)$ & $(0.6297)$ & $(0.5597)$ & $(0.5447)$ & $(0.1708)$ \\
\hline \multirow[t]{2}{*}{ Calificados } & 0.6993 & -0.1947 & 0.4900 & 0.9297 & -0.0804 \\
\hline & $(1.5117)$ & $(0.5890)$ & $(0.6694)$ & $(0.5762)$ & $(0.1983)$ \\
\hline \multirow[t]{2}{*}{ Jefe de hogar } & -0.9312 & 0.0334 & 0.0187 & 1.1660 & $-0.4215 * *$ \\
\hline & $(1.0399)$ & $(0.7546)$ & $(0.6397)$ & $(0.7228)$ & $(0.1753)$ \\
\hline \multirow[t]{2}{*}{ Menores de cinco años en el hogar } & $-2.5925^{* *}$ & -0.2607 & $-0.7095^{*}$ & -0.6188 & -0.1059 \\
\hline & $(1.0666)$ & $(0.3114)$ & $(0.3654)$ & $(0.4502)$ & $(0.1010)$ \\
\hline \multirow[t]{2}{*}{ Menos de 1 año de antigüedad } & $-2.2670^{*}$ & $-2.4755^{* * *}$ & $-1.6284 * * *$ & $-1.8583 * *$ & $-0.7104 * * *$ \\
\hline & $(1.2694)$ & $(0.6558)$ & $(0.6091)$ & $(0.8973)$ & $(0.2466)$ \\
\hline \multirow[t]{2}{*}{ Entre 1 a 5 años de antigüedad } & -1.7410 & -0.4691 & -0.7404 & -0.3598 & $-0.5097 * * *$ \\
\hline & $(1.0947)$ & $(0.5329)$ & $(0.5278)$ & $(0.6532)$ & $(0.1548)$ \\
\hline \multirow[t]{2}{*}{ Construc., comercio, rest. y hoteles } & - & - & $-3.9082 * * *$ & -0.7000 & -0.1121 \\
\hline & - & - & $(1.0797)$ & $(0.5449)$ & $(0.1916)$ \\
\hline \multirow[t]{2}{*}{ Servicios finan., inmobiliarios y empre. } & $1.5824^{*}$ & 0.1224 & -0.7234 & -0.0106 & $-0.7737 * * *$ \\
\hline & $(0.9138)$ & $(0.6287)$ & $(0.5375)$ & $(0.5387)$ & $(0.1923)$ \\
\hline \multirow[t]{2}{*}{ Serv. adm. pública, educ., salud y serv. soc. } & $-2.2559^{* *}$ & -0.5341 & $-1.7153 * * *$ & -0.3459 & 0.2335 \\
\hline & $(1.1204)$ & $(0.8932)$ & $(0.6606)$ & $(0.6985)$ & $(0.2465)$ \\
\hline \multirow[t]{2}{*}{ GBA } & - & - & -0.1051 & -0.3694 & 0.0004 \\
\hline & - & - & $(0.6647)$ & (1.0048) & $(0.1652)$ \\
\hline \multirow[t]{2}{*}{ NOA y NEA } & 0.9460 & $1.1531 *$ & $1.1478^{*}$ & 0.2812 & 0.0132 \\
\hline & $(1.0822)$ & $(0.6180)$ & $(0.6052)$ & $(0.9427)$ & $(0.1555)$ \\
\hline \multirow[t]{2}{*}{ Cuyo } & -0.0055 & $1.0561 *$ & 0.8704 & -0.0497 & 0.2024 \\
\hline & (1.0158) & $(0.5485)$ & $(0.6259)$ & $(0.9732)$ & $(0.1632)$ \\
\hline \multirow[t]{2}{*}{ Medianas empresas } & - & - & $-4.0223 * * *$ & 0.2219 & 0.2253 \\
\hline & - & - & $(1.2382)$ & $(1.1930)$ & $(0.3195)$ \\
\hline \multirow[t]{2}{*}{ Grandes empresas } & $-1.5345^{*}$ & $-2.3120 * * *$ & $-1.5248 * * *$ & -0.5917 & 0.0163 \\
\hline & $(0.9147)$ & $(0.5870)$ & $(0.5701)$ & $(0.5758)$ & $(0.1445)$ \\
\hline \multirow[t]{2}{*}{ Ingreso laboral mensual } & 0.0005 & -0.0004 & 0.0002 & $0.0018^{* * *}$ & $0.0003 * * *$ \\
\hline & $(0.0004)$ & $(0.0006)$ & $(0.0004)$ & $(0.0005)$ & $(0.0001)$ \\
\hline \multirow[t]{2}{*}{ Constante } & -3.1919 & $-3.4829 * * *$ & -2.5865 & $-4.9378 * *$ & $0.6287^{*}$ \\
\hline & $(2.2788)$ & (1.3433) & $(1.5900)$ & $(2.3215)$ & $(0.3524)$ \\
\hline Observaciones & 148 & 720 & 868 & 720 & 3,492 \\
\hline
\end{tabular}

Fuente: Elaborado a partir de los microdatos de la EPH.

Nota: Entre paréntesis se presentan los errores estándares. Tienen nivel educativo bajo los individuos con menos de secundario incompleto, nivel educativo medio, aquellos con secundario completo o universitario incompleto y nivel educativo alto, quienes completaron el nivel universitario. 
Cuadro A13. Modelo Logit de la tasa de entrada a puestos de trabajo de calidad, 2006-2007

\begin{tabular}{|c|c|c|c|c|c|}
\hline Variables & AISD $-->$ AFSD & AICD $-->$ AFSD & AI $\ldots$ AFSD & AICD $-->$ AISD & AFCD $\leadsto$ AFSD \\
\hline \multirow[t]{2}{*}{ Varón } & $-3.9082 * * *$ & -0.6296 & $-1.1979 * * *$ & 0.8528 & -0.3041 \\
\hline & $(1.3881)$ & $(0.7582)$ & $(0.4474)$ & $(0.6078)$ & $(0.1942)$ \\
\hline \multirow[t]{2}{*}{ Joven de 15 a 29 años } & 3.3622 & $2.0053^{* * *}$ & $1.2296^{*}$ & 0.2183 & -0.4758 \\
\hline & $(2.1624)$ & $(0.7366)$ & $(0.7183)$ & $(1.0059)$ & $(0.3119)$ \\
\hline \multirow[t]{2}{*}{ Adulto de edad central ( 30 a 49 años) } & 2.8536 & 0.3487 & 0.3179 & -0.8468 & -0.3398 \\
\hline & $(1.8285)$ & $(0.7516)$ & $(0.6193)$ & $(0.8853)$ & $(0.2277)$ \\
\hline \multirow[t]{2}{*}{ Nivel ed. bajo } & -0.7063 & 0.7754 & 0.9283 & -1.2485 & -0.0487 \\
\hline & $(1.1575)$ & $(1.2131)$ & $(0.7040)$ & $(0.9419)$ & $(0.2682)$ \\
\hline \multirow[t]{2}{*}{ Nivel ed. medio } & -1.0612 & $1.9940^{* * *}$ & $1.5261^{* * *}$ & -0.7411 & 0.2926 \\
\hline & $(1.6218)$ & $(0.6986)$ & $(0.4883)$ & $(0.9071)$ & $(0.2142)$ \\
\hline \multirow[t]{2}{*}{ Calificados } & -1.8899 & $1.6727^{* *}$ & $1.0109 *$ & 1.0481 & 0.1587 \\
\hline & $(1.4164)$ & $(0.7242)$ & $(0.5415)$ & $(0.6558)$ & $(0.2688)$ \\
\hline \multirow[t]{2}{*}{ Jefe de hogar } & -1.0077 & 1.1134 & 0.9332 & 0.7751 & 0.0808 \\
\hline & $(1.2861)$ & $(0.9754)$ & $(0.7899)$ & $(0.5963)$ & $(0.2449)$ \\
\hline \multirow[t]{2}{*}{ Menores de cinco años en el hogar } & -4.9549 & -0.2091 & -0.5830 & $-0.9580^{* *}$ & -0.1505 \\
\hline & $(3.3689)$ & $(0.4973)$ & $(0.4478)$ & $(0.4119)$ & $(0.1284)$ \\
\hline \multirow[t]{2}{*}{ Menos de 1 año de antigüedad } & $-3.2101 * *$ & -0.8586 & $-1.1218^{*}$ & $-1.9978 * * *$ & -0.2331 \\
\hline & $(1.4712)$ & $(0.6669)$ & $(0.6336)$ & $(0.6528)$ & $(0.3138)$ \\
\hline \multirow[t]{2}{*}{ Entre 1 a 5 años de antigüedad } & -0.6034 & -0.1321 & -0.3744 & -0.0814 & -0.0782 \\
\hline & $(0.9310)$ & $(0.5482)$ & $(0.5290)$ & $(0.5989)$ & $(0.1991)$ \\
\hline \multirow[t]{2}{*}{ Construc., comercio, rest. y hoteles } & $5.6516^{* * *}$ & $-3.1991 * * *$ & $-1.5060 * * *$ & -0.0825 & -0.0918 \\
\hline & $(2.1510)$ & $(0.8118)$ & $(0.5486)$ & $(0.7027)$ & $(0.2344)$ \\
\hline \multirow[t]{2}{*}{ Servicios finan., inmobiliarios y empre. } & -0.6081 & -1.3512 & $-1.1604 * *$ & -1.2016 & 0.1062 \\
\hline & $(1.5224)$ & $(0.8927)$ & $(0.5168)$ & $(0.7569)$ & $(0.2350)$ \\
\hline \multirow{2}{*}{ Serv. adm. pública, educ., salud y serv. soc. } & $3.9718^{* *}$ & 0.2429 & 0.3406 & -0.9419 & -0.0874 \\
\hline & $(1.9584)$ & $(0.8138)$ & $(0.6230)$ & $(0.8918)$ & $(0.3157)$ \\
\hline \multirow[t]{2}{*}{ GBA } & $-5.0667^{*}$ & -0.9944 & -0.3598 & $-1.5944^{* *}$ & 0.2807 \\
\hline & $(2.7125)$ & $(0.9740)$ & $(0.6264)$ & $(0.7665)$ & $(0.2211)$ \\
\hline \multirow[t]{2}{*}{ NOA y NEA } & $-6.4048 * *$ & -0.0384 & 0.0820 & 0.2765 & 0.1558 \\
\hline & $(3.1451)$ & $(0.8722)$ & $(0.6114)$ & $(0.7277)$ & $(0.2190)$ \\
\hline \multirow[t]{2}{*}{ Cuyo } & -0.7685 & 0.3997 & 0.5033 & -0.1554 & $0.6559 * * *$ \\
\hline & $(2.5649)$ & $(0.8388)$ & $(0.6281)$ & $(0.8091)$ & $(0.2124)$ \\
\hline \multirow[t]{2}{*}{ Medianas empresas } & $-2.2567^{*}$ & $-3.0112 * * *$ & $-1.9706 * * *$ & $1.3252^{* *}$ & $-0.4593^{*}$ \\
\hline & $(1.3070)$ & $(0.9749)$ & $(0.6222)$ & $(0.6612)$ & $(0.2551)$ \\
\hline \multirow{2}{*}{ Grandes empresas } & -2.1487 & -0.4632 & -0.7330 & $1.6761^{* * *}$ & 0.0052 \\
\hline & $(1.4770)$ & $(0.4639)$ & $(0.4527)$ & $(0.6475)$ & $(0.1813)$ \\
\hline \multirow[t]{2}{*}{ Ingreso laboral mensual } & $-0.0088 * * *$ & $0.0015^{* * *}$ & $0.0008^{*}$ & -0.0004 & 0.0003 \\
\hline & $(0.0033)$ & $(0.0005)$ & $(0.0004)$ & $(0.0008)$ & $(0.0002)$ \\
\hline \multirow[t]{2}{*}{ Constante } & $9.2962 * *$ & $-5.3802 * * *$ & $-3.0172 * *$ & $-3.5819^{* *}$ & $-0.9065^{*}$ \\
\hline & (3.8939) & $(1.7168)$ & $(1.3583)$ & $(1.5871)$ & $(0.4835)$ \\
\hline Observaciones & 109 & 441 & 550 & 441 & 1,392 \\
\hline
\end{tabular}

Fuente: Elaborado a partir de los microdatos de la EPH.

Nota: Entre paréntesis se presentan los errores estándares. Tienen nivel educativo bajo los individuos con menos de secundario incompleto, nivel educativo medio, aquellos con secundario completo o universitario incompleto y nivel educativo alto, quienes completaron el nivel universitario. 
Cuadro A14. Modelo Logit de la tasa de entrada a puestos de trabajo de calidad, 2012-2013

\begin{tabular}{|c|c|c|c|c|c|}
\hline Variables & AISD -.> AFSD & AICD $\ldots$ AFSD & AI $\rightarrow>$ AFSD & AICD -.> AISD & AFCD $\ldots$ AFSD \\
\hline \multirow[t]{2}{*}{ Varón } & -0.8865 & $-1.7222 * * *$ & $-1.2856^{* * *}$ & $1.3468 * *$ & 0.2683 \\
\hline & $(0.6106)$ & $(0.4965)$ & $(0.3351)$ & $(0.5617)$ & $(0.2412)$ \\
\hline \multirow[t]{2}{*}{ Joven de 15 a 29 años } & 0.2767 & 0.5184 & 0.4061 & -0.1327 & 0.1548 \\
\hline & $(1.0694)$ & $(0.6818)$ & $(0.5998)$ & $(0.6043)$ & $(0.3244)$ \\
\hline \multirow[t]{2}{*}{ Adulto de edad central ( 30 a 49 años) } & $2.2850 * *$ & -0.0493 & 0.6947 & -0.3098 & -0.1042 \\
\hline & $(0.8975)$ & $(0.7576)$ & $(0.5970)$ & $(0.5981)$ & $(0.2513)$ \\
\hline \multirow[t]{2}{*}{ Nivel ed. bajo } & $-3.1535^{* * *}$ & $-1.4789^{*}$ & $-1.3507 * *$ & -1.2296 & $-0.6176^{* *}$ \\
\hline & $(1.0574)$ & $(0.8253)$ & $(0.5971)$ & $(0.8348)$ & $(0.3047)$ \\
\hline \multirow[t]{2}{*}{ Nivel ed. medio } & 0.2245 & -0.3207 & 0.0288 & -0.8297 & $-0.7180 * * *$ \\
\hline & $(0.6740)$ & $(0.5876)$ & $(0.4822)$ & $(0.6451)$ & $(0.2352)$ \\
\hline \multirow[t]{2}{*}{ Calificados } & 0.1140 & $2.0199 * * *$ & $1.0137 * * *$ & -0.0904 & -0.0355 \\
\hline & $(0.7375)$ & $(0.5030)$ & $(0.3705)$ & $(0.5165)$ & $(0.3073)$ \\
\hline \multirow[t]{2}{*}{ Jefe de hogar } & 0.9182 & $-1.2045^{* * *}$ & $-0.7704 * *$ & $1.7309 * * *$ & 0.0900 \\
\hline & $(0.7373)$ & $(0.4633)$ & $(0.3664)$ & $(0.5996)$ & $(0.3058)$ \\
\hline \multirow[t]{2}{*}{ Menores de cinco años en el hogar } & $1.0883 * *$ & -0.0602 & 0.3421 & $-1.7356^{* * *}$ & 0.0350 \\
\hline & $(0.4564)$ & $(0.3914)$ & $(0.3057)$ & $(0.5526)$ & $(0.1589)$ \\
\hline \multirow[t]{2}{*}{ Menos de 1 año de antigüedad } & -0.3354 & -0.1474 & 0.0705 & -0.2791 & $-1.2540 * * *$ \\
\hline & $(0.8244)$ & $(0.6775)$ & $(0.4947)$ & $(0.7373)$ & $(0.3436)$ \\
\hline \multirow[t]{2}{*}{ Entre 1 a 5 años de antigüedad } & 0.1099 & -0.5064 & -0.2348 & 0.4250 & $-0.4550^{* *}$ \\
\hline & $(0.7135)$ & $(0.4760)$ & $(0.4166)$ & $(0.5444)$ & $(0.2146)$ \\
\hline \multirow[t]{2}{*}{ Construc., comercio, rest. y hoteles } & $-4.3437 * * *$ & $1.5117 * *$ & 0.4914 & 0.0105 & $-0.7011 * *$ \\
\hline & $(1.1962)$ & $(0.6443)$ & $(0.5782)$ & $(0.5846)$ & $(0.3036)$ \\
\hline \multirow[t]{2}{*}{ Servicios finan., inmobiliarios y empre. } & $-1.9234 * * *$ & 0.9065 & -0.2205 & $-1.3070^{* *}$ & $-0.5752 * *$ \\
\hline & $(0.7299)$ & $(0.6641)$ & $(0.4888)$ & $(0.6033)$ & $(0.2509)$ \\
\hline \multirow[t]{2}{*}{ Serv. adm. pública, educ., salud y serv. soc. } & $-2.5868 * *$ & -1.0507 & $-1.6254 * *$ & -0.8410 & -0.4543 \\
\hline & $(1.1989)$ & $(0.9806)$ & $(0.6909)$ & $(0.8206)$ & $(0.3237)$ \\
\hline \multirow[t]{2}{*}{ GBA } & -1.4350 & $-1.4698^{* *}$ & $-1.0744 * *$ & 1.1592 & 0.2903 \\
\hline & $(0.9845)$ & $(0.6029)$ & $(0.5063)$ & $(0.8631)$ & $(0.2704)$ \\
\hline \multirow[t]{2}{*}{ NOA y NEA } & -0.3684 & -0.6391 & -0.6911 & 1.0755 & 0.3935 \\
\hline & $(1.0873)$ & $(0.5764)$ & $(0.4820)$ & $(0.8650)$ & $(0.2541)$ \\
\hline \multirow[t]{2}{*}{ Cuyo } & -0.3721 & -0.7145 & -0.3288 & 0.9753 & $0.4782 *$ \\
\hline & $(1.3218)$ & $(0.5826)$ & $(0.4555)$ & $(0.9253)$ & $(0.2527)$ \\
\hline \multirow[t]{2}{*}{ Medianas empresas } & -0.2856 & -0.9118 & $-1.2123 * *$ & $1.4417 * *$ & 0.3051 \\
\hline & $(0.8387)$ & $(0.7400)$ & $(0.5658)$ & $(0.7209)$ & $(0.3250)$ \\
\hline \multirow[t]{2}{*}{ Grandes empresas } & -0.3152 & 0.0863 & -0.3064 & $1.3089^{*}$ & 0.1732 \\
\hline & $(0.7249)$ & $(0.5158)$ & $(0.4653)$ & $(0.7003)$ & $(0.2051)$ \\
\hline \multirow[t]{2}{*}{ Ingreso laboral mensual } & -0.0009 & 0.0008 & -0.0002 & 0.0008 & -0.0001 \\
\hline & $(0.0006)$ & $(0.0007)$ & $(0.0004)$ & $(0.0006)$ & $(0.0002)$ \\
\hline \multirow[t]{2}{*}{ Constante } & -1.3729 & -1.0487 & -0.2957 & $-5.1256^{* * *}$ & 0.0885 \\
\hline & $(1.3512)$ & (1.3789) & $(0.9401)$ & $(1.7414)$ & $(0.5865)$ \\
\hline Observaciones & 226 & 386 & 612 & 386 & 1,251 \\
\hline
\end{tabular}

Fuente: Elaborado a partir de los microdatos de la EPH.

Nota: Entre paréntesis se presentan los errores estándares. Tienen nivel educativo bajo los individuos con menos de secundario incompleto, nivel educativo medio, aquellos con secundario completo o universitario incompleto y nivel educativo alto, quienes completaron el nivel universitario. 


\section{Cuadro A15. Modelo Logit de la probabilidad de estar ocupado en un puesto informal en las MGEySP, 1995-2013}

\begin{tabular}{|c|c|c|c|c|}
\hline Variables & 1996-1997 & 2001-2002 & $2006-2007$ & 2012-2013 \\
\hline \multirow[t]{2}{*}{ Varón } & 0.0815 & 0.0121 & 0.1513 & $0.3217 * *$ \\
\hline & $(0.1200)$ & $(0.1219)$ & $(0.1183)$ & $(0.1294)$ \\
\hline \multirow[t]{2}{*}{ Joven de 15 a 29 años } & -0.1501 & -0.1366 & 0.0335 & -0.0640 \\
\hline & $(0.1506)$ & $(0.1653)$ & $(0.1631)$ & $(0.1919)$ \\
\hline \multirow[t]{2}{*}{ Adulto de edad central ( 30 a 49 años) } & $-0.4411 * * *$ & $-0.4344 * * *$ & $-0.2584 *$ & -0.2306 \\
\hline & $(0.1306)$ & $(0.1334)$ & $(0.1329)$ & $(0.1485)$ \\
\hline \multirow[t]{2}{*}{ Nivel educativo bajo } & $1.0175 * * *$ & 0.2433 & $0.7604 * * *$ & $0.9968 * * *$ \\
\hline & $(0.1675)$ & $(0.1512)$ & $(0.1668)$ & $(0.1796)$ \\
\hline \multirow[t]{2}{*}{ Nivel educativo medio } & $0.6342 * * *$ & 0.1383 & $0.2320^{*}$ & $0.3244 * *$ \\
\hline & $(0.1563)$ & $(0.1303)$ & $(0.1345)$ & $(0.1398)$ \\
\hline \multirow[t]{2}{*}{ Calificados } & $-0.2101^{*}$ & $-0.3975 * * *$ & -0.1831 & -0.2451 \\
\hline & $(0.1250)$ & $(0.1349)$ & $(0.1560)$ & $(0.1628)$ \\
\hline \multirow[t]{2}{*}{ Menores de cinco años en el hogar } & -0.0881 & -0.0352 & -0.0863 & -0.1305 \\
\hline & $(0.0681)$ & $(0.0826)$ & $(0.0885)$ & $(0.0953)$ \\
\hline \multirow[t]{2}{*}{ Conyugue de hogar } & $0.7697 * * *$ & $0.4404 * *$ & $0.7825 * * *$ & $0.4751 * *$ \\
\hline & $(0.2059)$ & $(0.1881)$ & $(0.1940)$ & $(0.2022)$ \\
\hline \multirow{2}{*}{ Jefe de hogar ocupado como asal. formal } & $-0.4562 *$ & $-0.6579 * * *$ & $-1.0399 * * *$ & $-1.2928 * * *$ \\
\hline & $(0.2430)$ & $(0.2267)$ & $(0.2059)$ & $(0.2250)$ \\
\hline \multirow[t]{2}{*}{ Cony. de hogar*Jefe de hogar ocupado asal. formal } & $-0.6793 * *$ & -0.1223 & -0.0911 & 0.0735 \\
\hline & $(0.2726)$ & $(0.2652)$ & $(0.2465)$ & $(0.2691)$ \\
\hline \multirow[t]{2}{*}{ Menos de 1 año de antigüedad } & $1.1332 * * *$ & $0.8763 * * *$ & $1.1801 * * *$ & $0.8788 * * *$ \\
\hline & $(0.1379)$ & $(0.1528)$ & $(0.1698)$ & $(0.1979)$ \\
\hline \multirow[t]{2}{*}{ Entre 1 a 5 años de antigüedad } & $0.2978 * *$ & $0.2832 * *$ & $0.5498 * * *$ & $0.6302 * * *$ \\
\hline & $(0.1200)$ & $(0.1258)$ & $(0.1267)$ & $(0.1385)$ \\
\hline \multirow[t]{2}{*}{ Construc., comercio, rest. y hoteles } & 0.1943 & 0.0466 & 0.2314 & $-0.7893 * * *$ \\
\hline & $(0.1340)$ & $(0.1469)$ & $(0.1537)$ & $(0.1815)$ \\
\hline \multirow[t]{2}{*}{ Servicios finan., inmobiliarios y empre. } & 0.0241 & 0.1579 & $-0.2882 * *$ & $-0.4737 * * *$ \\
\hline & $(0.1383)$ & $(0.1347)$ & $(0.1445)$ & $(0.1529)$ \\
\hline \multirow{2}{*}{ Serv. adm. pública, educ., salud y serv. soc. } & -0.2201 & $-0.4101 * *$ & 0.0122 & -0.2904 \\
\hline & $(0.2091)$ & $(0.1919)$ & $(0.1950)$ & $(0.1895)$ \\
\hline \multirow[t]{2}{*}{ NOA } & $0.3422 * * *$ & -0.0127 & $0.2596^{* *}$ & 0.0059 \\
\hline & $(0.1196)$ & $(0.1134)$ & $(0.1208)$ & $(0.1263)$ \\
\hline \multirow[t]{2}{*}{ NEA } & -0.0539 & $-0.4252 * * *$ & 0.0146 & $-0.3883^{* *}$ \\
\hline & $(0.1130)$ & $(0.1428)$ & $(0.1802)$ & $(0.1598)$ \\
\hline \multirow[t]{2}{*}{ Cuyo } & $0.2283^{*}$ & -0.0119 & 0.1461 & -0.0015 \\
\hline & $(0.1197)$ & $(0.1251)$ & $(0.1371)$ & $(0.1482)$ \\
\hline \multirow[t]{2}{*}{ Pampa } & -0.0486 & -0.1358 & $-0.2168^{*}$ & $-0.6657 * * *$ \\
\hline & $(0.1017)$ & $(0.1145)$ & $(0.1181)$ & $(0.1362)$ \\
\hline \multirow[t]{2}{*}{ Patagonia } & $-0.8266^{* * *}$ & $-0.4617 * * *$ & $-0.7671 * * *$ & $-1.0474 * * *$ \\
\hline & $(0.1211)$ & $(0.1215)$ & $(0.1948)$ & $(0.1727)$ \\
\hline \multirow[t]{2}{*}{ Medianas empresas } & $0.6990 * * *$ & 0.0631 & $0.3517 * *$ & $0.8176^{* * *}$ \\
\hline & $(0.2394)$ & $(0.2632)$ & $(0.1560)$ & $(0.1763)$ \\
\hline \multirow[t]{2}{*}{ Grandes empresas } & $0.4153 * * *$ & $0.2546^{* *}$ & $0.2069^{*}$ & 0.1738 \\
\hline & $(0.1127)$ & $(0.1180)$ & $(0.1197)$ & $(0.1298)$ \\
\hline \multirow[t]{2}{*}{ Constante } & $-2.2308 * * *$ & $-1.1739 * * *$ & $-1.4133 * * *$ & $-1.0625 * * *$ \\
\hline & $(0.3008)$ & $(0.2684)$ & $(0.2828)$ & $(0.3152)$ \\
\hline Observaciones & 10,634 & 7,275 & 4,445 & 5,709 \\
\hline
\end{tabular}

Fuente: Elaborado a partir de los microdatos de la EPH.

Nota: Entre paréntesis se presentan los errores estándares. Tienen nivel educativo bajo los individuos con menos de secundario incompleto, nivel educativo medio, aquellos con secundario completo o universitario incompleto y nivel educativo alto, quienes completaron el nivel universitario. 


\section{REFERENCIAS}

Alcaraz, Carlos (2015). Informal and Formal Labour Flexibility in Mexico. Desarrollo y Sociedad $\mathrm{N}^{\circ}$ 63. Bogotá.

Alexander, Arthur J. (1974). Income, Experience and Internal Labour Markets, Quarterly Journal of Economics, 88, 63-85.

Alzúa, María Laura (2008). Are Informal Workers Secondary Workers?: Evidence for Argentina. Documento de Trabajo $N^{\circ} 73$. CEDLAS. Universidad Nacional de La Plata.

Arias, Omar y Melanie Khamis (2008). Comparative Advantage, Segmentation and Informal Earnings: A Marginal Treatment Effects Approach. Institute for the Study of Labor (IZA), Discussion Paper Nº 3916.

Banco Mundial y MTEySS (2008). Aportes a una nueva visión de la informalidad laboral en la Argentina. Buenos Aires: Banco Mundial y Ministerio de Trabajo, Empleo y Seguridad Social.

Beccaria, Luis, Fernando Groisman y P. Monsalvo, (2006). Informalidad y Pobreza en Argentina, Anales de la Asociación Argentina de Economía Política, Buenos Aires. Disponible en: www. aaep.or.ar

Bentolila, Samuel, Pierre Cahuc, Juan J. Dolado y Thomas Le, Barbanchon (2010). Two-Tier Labor Markets in the Great Recession: France vs. Spain. IZA Discussion Paper No. 5340.

Bernhardt, Inwin (1994). Comparative Advantage in Self-Employment and Paid Work. Canadian Journal of Economics, 27(2), 273-289.

Bertranou, Fabio, Luis Casanova y Marianela Sarabia (2013). Dónde, cómo y por qué se redujo la informalidad laboral en Argentina durante el periodo 2003-2012. OIT.

Bertranou, Fabio, Luis Casanova, Maribel Jiménez y Mónica Jiménez (2014). Informalidad, Calidad del Empleo y segmentación laboral en Argentina, 1990-2011, Revista de Economía Laboral, 11, 24-64.

Bertranou, Fabio, Raúl Mercau, Silvia Jardel y Rodrigo González (2011). Informalidad laboral en la provincia de Mendoza: características y politicas para promover la formalización. Buenos Aires, Oficina Internacional del Trabajo.

Bosch, Mariano y William Maloney (2008). Cyclical Movements in Enemployment and Informality in Developing Countries, The World Bank Policy Research Working Paper, 4648.

Casal, María del Pilar y Barham L. Bradford (2013). Penalizaciones salariales por maternidad y segmentación del mercado laboral: el caso de la Argentina. Revista CEPAL 111, 59-81.

Casanova, Luis y Javier Alejo (2014). El rol de la negociación colectiva en la distribución de los ingresos laborales. Evidencia empirica para Argentina en los dos mil. Buenos Aires: Oficina de País de la OIT para la Argentina.

De Soto, Hernando (1989). The Other Path. Nueva York: Basic Books.

Deakin, Simon (2013). Addressing labour market segmentation: The role of labour law. Working paper $\mathrm{N}^{\circ} 52$, OIT.

Dickens, William T. y Kevin Lang (1985). A Test of Dual Labor Market Theory. NBER, Working paper $\mathrm{N}^{\circ} 1384$.

Doeringer, Peter B. y J. Michael Piore (1971). Internal Labor Markets and Manpower Analysis. Lexington, MA: Heath Lexington Books.

Fernández Huerga, Eduardo (2010). La teoría de la segmentación del mercado de trabajo: enfoques, situación actual y perspectivas de futuro. Investigación Económica, 69(273), 115-150. 
Fernández Massi, Mariana (2014). Segmentación del mercado de trabajo y estructura productiva: un análisis del empleo sectorial en Argentina. Buenos Aires: Facultad de Ciencias Sociales Universidad de Buenos Aires.

Fields, G. S. (2004). A Guide to Multisector Labor Market Models. Washington, DC: Banco Mundial, noviembre.

Fields, Gary S. (1975). Rural-Urban Migration, Urban Unemployment and Underemployment, and Job Search Activities in ldcs. Journal of Development Economics, 2, 165-187.

Fields, Gary S. (1990). Labour Market Modelling and the Urban Informal Sector: Theory and Evidence. En D. Turnham, B. Salomé y A. Scharz (eds.), The informal sector revisited (pp. 49-69). París: Organisation for Economic Co-operation and Development.

Fields, Gary S. (2005). A guide to multisector labor market models. Paper prepared for the World Bank Labor Market Conference.

Fields, Gary S. (2008). Segmented Labor Market Models in Developing Countries. ILR Collection Articles and Chapters. Ithaca: Cornell University ILR School. Marzo.

Galiani, Sebastián y Weinschelbaum, Federico (2012). Modelling informality formally: housholds and firms. Economic Inquiry, 50(3), 821-838.

Galli, Rossana y David Kucera (2004). Labor Standards and Informal Employment in Latin America. World Development, 32(5), 809-828.

Gasparini, Leonardo y Leopoldo Tornarolli (2007). Labor Informality in Latin American and the Caribbean: Patterns and Trends from Household Surveys Microdata. CEDLAS, Documento de Trabajo No 46. La Plata, febrero.

Günther, Isabel y Andrey Launov (2012). Informal employment in developing countries: Opportunity or last resort? Journal of Development Economics, 97(1), 88-98.

Harati, Rawaa (2013). Heterogeneity in the Egyptian informal labour market: choice or obligation? Revue d'économie politique, 123(4), 623-639.

Harris, Jhon R. y Michael Todaro (1970). Migration, Unemployment, and Development: A Two-Sector Analysis. American Economic Review, 60, 126-142.

Heckman, James (1979). Sample selection as a specification error. Econometrica, 47, 153-161.

Heckman, James y Carmen Pages (2004). Law and Employment Lessons from Latin America and The Caribbean. Chicago: The University of Chicago Press.

Hirsh, Boris (2016). "Dual Labor Markets at Work: The Impact of Employers' Use of Temporary Agency Work on Regular Workers' Job Stability”, forthcoming.

Huesca Reynoso, Luis (2005). La distribución salarial del mercado de trabajo en México: un análisis de la informalidad laboral. Barcelona: Universidad Autónoma de Barcelona.

Hussmanns, Ralf (2004). Defining and Measuring Informal Employment. Ginebra: OIT.

Instituto Nacional de Estadística y Censos (INDEC) (2003). La nueva encuesta permanente de hogares de Argentina. Buenos Aires, INDEC.

Jiménez, Mónica (2011). La economía informal y el mercado laboral en la Argentina: un análisis desde la perspectiva del trabajo decente. Documento de trabajo, 116. La Plata: CEDLAS, Universidad Nacional de La Plata.

Jiménez, Mónica (2013). La informalidad laboral en el sector formal de la Argentina. Un análisis preliminar. Working Paper $\mathrm{N}^{\circ} 10$. Salta: Instituto de Estudios Laborales y del Desarrollo Económico (IELDE), Facultad de Ciencias Económicas, Jurídicas y Sociales, Universidad Nacional de Salta. Disponible en www.economicas.unsa.edu.ar/ielde/

Kerr, Claik (1954 The Balcanization of Labour Markets, in Labour Mobility and Economic Opportunity. Cambridge, MA: MIT Press. 
Kumaş Handan, Atalay Çağlar y Hacer Simay Karaalp (2014). Firm Size and Labour Market Segmentation Theory: Evidence from Turkish Micro Data. Social and Behavioral Sciences, 150(15), 360-373.

Lewis, Arthur W. (1954). Economic Development with Unlimited Supplies of Labour. Manchester School, 22, 139-191.

Loayza, Norman V. y Jamele Rigolini (2012). Informal Employment: Safety Net or Growth Engine? World Development, 39, 1503-1515.

Magnac, Thierry (1991). Segmented or Competitive Labor Markets. Econometrica, 59, 165-187. Maloney, William F. (1999). Does Informality Imply Segmentation in Urban Labor Markets? Evidence from Sectorial Transitions in Mexico. The World Bank Economic Review, 13, 275-302.

Maloney, William F. (2004). Informality Revisited. World Development, 32(7), 1159-1178.

Martínez Soria, Jesuswaldo (2008). Empleo informal y segmentación del mercado de trabajo urbano en México. Tesis de doctorado no publicada, Departamento de Economía Aplicada, Universidad Autónoma de Barcelona.

Maurizio, Roxana (2012). Labour Informality in Latin America: The Case of Argentina, Chile, Brazil and Peru. BWPI, Working Paper 165. Universidad Nacional de General Sarmiento.

McDonald, Ian M. y Robert M. Solow (1985 Wages and Employment in a Segmented Labor Market. Quarterly Journal of Economics, 100(4), 1115-1141.

Ministerio de Trabajo, Empleo y Seguridad Social (MTEySS) y Banco Mundial (BM) (2008). La Informalidad laboral en el Gran Buenos Aires. Una nueva mirada, Buenos Aires: MTEySS y BM.

Ministerio de Trabajo, Empleo y Seguridad Social (MTEySS)-Banco Mundial-INDEC (2007). Una nueva mirada al problema de la informalidad laboral. Buenos Aires: MTEySS, BM e INDEC.

MTEySS (2014). Protección y seguridad social en Argentina. Resultados de la Encuesta Nacional sobre Protección y Seguridad Social. Buenos Aires: Ministerio de Trabajo, Empleo y Seguridad Social.

Organización Internacional del Trabajo (2002). El trabajo decente y la economía informal, $90^{a}$ Conferencia Internacional del Trabajo, Ginebra.

Organización Internacional del Trabajo (2008). Decent Work Country Programme Argentina. Buenos Aires: Ministerio de Trabajo, Empleo y Seguridad Social.

Organización Internacional del Trabajo (2011). Trabajadores independientes, mercado laboral e informalidad en Argentina. Buenos Aires: OIT.

Perry, Guillero E., William Maloney, Omar Arias, Pablo, Fajnzylber, Andrew Mason y Jaime Saavedra (2007). Informality: Exit and Exclusion. Estudios del Banco Mundial sobre América Latina y el Caribe. Washington, DC: Banco Mundial. Disponible en: www.siteresources. worldbank.org/INTLAC/Resources.

Piore, Michael (1980). Los fundamentos tecnológicos del dualismo y de la discontinuidad. En L. Toharia, 1983. El mercado de trabajo: teorías y aplicaciones. Lecturas seleccionadas. Madrid: Alianza editorial.

Pomares, Julia, José Gasparin y Diego, Deleersnyder (2013). Evolución y distribución del empleo público en el sector público nacional argentino. Una primera aproximación. Documento de trabajo $N^{\circ} 117$, Centro de Implementación de Políticas Públicas para la Equidad y el Crecimiento (CIPPEC). 
Portes, Alejando, Manuel Castelles y Lauren Benton (1989). The informal economy: studies in advanced and less developed countries. Baltimore y Londres: The John Hopkins University Press.

Pratap, Sangeeta y Erwan Quintín (2006). Are Labour Markets Segmented in Developing Countries? A Semiparametric Approach. European Economic Review, 50, 507-542.

Rodgers, Gerry (1989). Precarious work in Western Europe: The state of the debate. En G. Rodgers y J. Rodgers (eds.), Precarious jobs in labour market regulation: The growth of atypical employment in Western Europe. Ginebra: International Labour Organization.

Ronconi, Lucas (2001). Informalidad laboral e inspección del trabajo en Argentina. Un enfoque institucional. Documento de Trabajo, No 46, CEDI, USA, Argentina.

Salem, Melika Ben, Isabelle Bensidoun y Selin Pelek (2011). Informal employment in Turkey: an overview. Région et développement, (34), 57-84.

Santarcángelo, Juan y Martín Schorr (2000). Desempleo y precariedad laboral en la Argentina durante la década de los noventa. Estudios del Ttrabajo $\mathrm{N}^{\circ} 20$. Buenos Aires.

Sharma, Anisha (2013). Informality, firm size, and labour market segmentation in Indonesia. Oxford: Centre for the Study of African Economies (CSAE) y Department of Economics, University of Oxford.

Svalund, Jørgen (2013). Labor Market Institutions, Mobility, and Dualization in the Nordic Countries. Nordic Journal of Working Life Studies, 3(1).

Taubman, Paul y Michael Wachter (1986). Segmented Labour Markets. En O. Ashenfelter y R. Layard (eds.), Handbook of Labour Economics (volume 2). Ámsterdam: North-Holland.

Tokman, Víctor E. (2001). De la informalidad a la modernidad. Santiago de Chile: Oficina Internacional del Trabajo, Andros impresores. Recuperado de http://www.oitchile.cl/pdf/ publicaciones/emp/emp005.pdf.

Vella, Francis (1998). Estimating models with sample selection bias: A survey. Journal of Human Resources, 3, 127-169.

Waisgrais, Sebastián (2001). Segmentación del mercado de trabajo en Argentina: una aproximación a través de la economía informal. Buenos Aires: Asociación Argentina de Especialista en Estudios del Trabajo. Disponible en: www.aset.org.ar 